Understanding the Contributions of Reallocation to Productivity Growth: Lessons from a Comparative Firm-Level Analysis

J. David Brown (Heriot-Watt University, Edinburgh) John S. Earle (Central European University and Upjohn Institute)

Berlin, September 2008 


\title{
Understanding the Contributions of Reallocation to Productivity Growth: Lessons from a Comparative Firm-Level Analysis
}

\author{
J. David Brown and John S. Earle* \\ July 2008
}

JEL Codes: E32, O47, P23

Keywords: productivity, reallocation, industry dynamics, creative destruction, reform, transition, Georgia, Hungary, Lithuania, Romania, Russia, Ukraine

\begin{abstract}
We analyze comprehensive manufacturing firm data to measure the contribution of interfirm employment reallocation to aggregate productivity growth during the socialist and reform periods in six transition economies. Modifying a standard decomposition technique to better reflect the role of firm entry, we find that reallocation rates and productivity contributions are very low under socialism. After reforms, they rise dramatically, and productivity contributions greatly exceed those observed in market economies. Early in transition, faster reform is associated with larger contributions from reallocation, but later, and on average over the whole transition, this relationship is reversed. Though reallocation rates are larger in faster reforming economies, higher productivity dispersion in slower reformers creates much higher productivity gains for a given volume of reallocation. The results imply that reallocation should be viewed as necessary regular maintenance for a well-functioning economy, and particularly large productivity contributions tend to reflect previous neglect more than current virtue.
\end{abstract}

*Heriot-Watt University, School of Management and Languages, Edinburgh EH14 4AS, United Kingdom (j.d.brown@hw.ac.uk); and Upjohn Institute for Employment Research, $300 \mathrm{~S}$. Westnedge Ave., Kalamazoo, MI 49007, and Central European University (CEU), Hungary (earlej@ceu.hu), respectively. We thank Álmos Telegdy for collaboration on related research, without which this paper could not have been written, and Eric Bartelsman, Rick Ericson, John Haltiwanger, Eric Livny, Mark Schaffer, and Chad Syverson for helpful comments. Data preparation required large teams of research assistants, and we are grateful for the careful work of Gabor Antal, Katalin Antal, Anna Horváth, Anna Lovász, Judit Mathé, Béla Személy, and Ágnes Töröcsik in Hungary; bana Dan, Victor Kaznovsky, Catalin Pauna, Irina Vantu, and especially Ruxandra Stefan in Romania; and Natalia Akhmina, Tatiana Andreyeva, Serhiy Biletsky, Larisa Leshchenko, Ivan Maryanchyk, Alexander Scherbakov, and especially Vladimir Vakhitov in Ukraine. We thank the Hungarian National Bank and EROC (Economic Research and Outreach Center in Kyiv) for cooperation and data support. The Hungarian and Romanian analyses were supported by a grant from the US State Department, and the Russian and Ukrainian analyses by the European Union's Sixth Framework Programme (Project ESCIRRU). All errors are our own. 


\section{Introduction}

Basic economics stresses the crucial role of resource allocation in achieving efficiency and implies, as a corollary, the importance of flexible reallocation in fostering economic growth. Until recently, however, data constraints have prevented empirical research from quantifying the magnitudes and contributions of reallocation. Comprehensive panel data on business units are required, for example, to measure the extent to which aggregate productivity growth is driven by productivity improvements within firms as opposed to resource reallocation from less to more productive firms. Research on these questions is still in its early stages, but some of it has already suggested substantial contributions of reallocation to aggregate productivity growth. ${ }^{1}$

This paper extends research on reallocation and productivity in several ways: data, methods, comparative analysis, and interpretation. We study a set of formerly socialist economies that have been engaged in the transition from central planning for more than a decade, countries that have not received a great deal of attention but that we will argue provide particularly interesting cases for investigating reallocation. We assemble comparable annual panel data with long time series on the universe (or near-universe) of manufacturing firms in six of these economies - Georgia, Hungary, Lithuania, Romania, Russia, and Ukraine - and we apply the same data-cleaning and statistical procedures to each of them, in order to obtain genuinely comparable results. Following previous studies of productivity-enhancing reallocation, our measurement approach relies on decompositions of aggregate productivity growth (particularly those of Haltiwanger, 1997; Foster, Haltiwanger, and Krizan, 2001); we propose a modified method that we argue better reflects the contribution from entry.

Why do some economies achieve more productivity growth via reallocation of resources from lower- to higher-valued uses? Many previous studies maintain, implicitly or explicitly, that higher contributions of reallocation to productivity growth result from better policy and business environments with lower costs of adjustment. While earlier research has usually focused on single economies in a narrow window of time, a logical next step is to use comparable microdata from different economic policy contexts to understand how these factors affect the pace and contributions of reallocation. $^{2}$

Exploiting the cross-country and time series dimensions of our data, we carry out a comparative analysis of reallocation and productivity across an extraordinary variety of policy settings. By all accounts, the socialist economies had poor innovation incentives and selection mechanisms, suggesting much weaker processes of creative destruction under central planning than in well-functioning market economies. The collapse of Communist rule and subsequent liberalization (in the early to mid-1990s) opened up pportunities for rapid restructuring to

\footnotetext{
${ }^{1}$ See, for instance, Baily, Hulten, and Campbell (1992) and Foster, Haltiwanger, and Krizan (2001) for the US; Griliches and Regev (1995) for Israel; Liu and Tybout (1996) for Chile and Columbia; Aw, Chen, and Roberts (2001) for Taiwan; Disney, Haskel, and Heden (2003) for the UK; and Bartelsman, Haltiwanger, and Scarpetta (2004) and Brown and Earle $(2002,2006)$ for a few transition economies.

${ }^{2}$ Variation in data (collection methods, coverage, frequency, and definitions), in cleaning procedures (particularly the construction of longitudinal links), and in decomposition methodologies usually make such comparisons difficult if not impossible, but our data are quite similar and we apply consistent methods of data preparation and analysis to the six countries. Bartelsman, Haltiwanger, and Scarpetta (2004) study the results produced by other researchers using a common program for several countries in the early to mid-1990s. Aw, Chung and Roberts (2003) compare productivity and turnover patterns in Taiwan and Korea in the 1980s, but they do not measure the productivity growth attributable to reallocation. Pavcnik (2002) and Eslava, Haltiwanger, Kugler, and Kugler (2004) are beforeand-after studies of the effects of reforms in single countries (Chile and Colombia, respectively).
} 
address the accumulated patterns of misallocation. The six economies we study adopted different speeds of policy reforms and therefore may exhibit different responses in this early transition period as well as in the later transition, when the economies stabilized and growth resumed (particularly after 2000). Our data enable comparisons of the pace and productivity contributions of reallocation across these varied settings, as well as to comparable figures for other economies that are available from previous research. To help account for the variation in the size of productivity contributions, we propose and implement a method to decompose the differences into three components: the dispersion of productivity, the pace of reallocation, and the correlation between reallocation and relative productivity across firms.

We find that the reallocation rates and contributions to aggregate productivity growth are quite different in our data on transition economies from the results that have been reported for other countries. They are different during the central planning years in that both the pace and contributions of reallocation in the economies we study are much lower than elsewhere. They are different after economic liberalization in that the contributions of reallocation to productivity growth become much higher than elsewhere. The pace of reallocation also rises quickly after reforms, but only to the levels of developed market economies (except for Hungary in the early 1990s and Georgia in the early 2000s, when it is much higher); in general, therefore, transition economies achieve larger productivity gains for roughly the same reallocation rates. Despite this anomaly, the results demonstrate both the small role of reallocation under central planning and the very effective creative destruction unleashed by economic liberalization. In this sense, our analysis strongly supports the conclusions of previous research on the productivity contributions of reallocation.

However, the magnitudes of these contributions differ considerably across the six economies we study. In Hungary, generally considered the fastest reformer among the six in our sample (as well as at or near the top among all transition economies), the reallocation contribution rises earlier than elsewhere and it reaches levels much higher than comparable figures for Western economies, but then it peaks quickly and declines to close to zero. Lagging reformers realize significant reallocation contributions more slowly, but when the contributions emerge they become still much higher than in Hungary or the West, and they persist through recent data. Contrary to conventional wisdom, the rank order across countries in the size of contributions of reallocation to productivity growth in the most recent period as well as over the whole transition is inversely correlated with reform speed.

Our decomposition of the cross-country and over-time differences sheds light on these patterns. Reallocation led to no productivity growth in the centrally planned economies not only because so little reallocation occurred, but also because of a very low correlation between reallocation and relative productivity at the firm level, particularly in Soviet Russia: the direction of resource reallocation had little relationship with relative productivities. The rise in productivity-enhancing reallocation during the transition is proportionately greater than the rise in the pace of reallocation because of simultaneous rises in the dispersion of productivity and the correlation between reallocation and relative productivity.

Comparing across countries, we find that the increase in productivity dispersion was larger in the slower reforming economies, subsequently engendering larger contributions of reallocation to productivity growth. The larger gaps in the slower reformers may have led to higher correlations between reallocation and relative productivity because greater dispersion makes it more obvious which firms should expand or contract. Overall, we interpret the negative relationship of reform speed and reallocation contribution as the consequence of slower reforms 
resulting in less cleansing of low productivity firms at the beginning of transition. Meanwhile, the faster reformers have had much better within-firm productivity growth, facilitated by the weeding out of worse performers, the encouragement of experimentation from new entrants, and the enhanced competitive pressure on surviving incumbents. The two main components of productivity growth - within-firm and reallocation - thus tend to be negatively correlated in a cross-section of countries.

Somewhat paradoxically, therefore, we find that reallocation matters most when it appears to matter least, in terms of direct productivity contributions. Fast reformers experience an initial boost of productivity growth due to reallocation just after liberalization, but within a few years the contribution is negligible. Slow reformers permit the productivity distribution to widen so much that reallocation contributions become large later on. These findings support a more nuanced view of the role of reallocation in which indirect effects of market pressures may be more important than the direct contributions of reallocation to productivity growth.

While these results may be surprising to some observers, we argue that they can be interpreted using standard models of industry dynamics. To take one example, costs of entry in these models have implications for firm turnover rates and the productivity cut-off level for exiting firms. Lower entry costs imply lower productivity levels of entrants relative to incumbents and higher productivity levels of exiting firms. Thus, if entry costs are negatively associated with the quality of the business and policy environment, then a better environment may produce smaller direct contributions of reallocation to aggregate productivity growth. The initial burst of high contributions in fast reforming economies reflects the accumulated misallocations of socialism, and the subsequent decline in contributions reflects an improved, not a worsened business environment. The later, but still larger contributions in the slower reformers result from a widening of productivity gaps that reflect the accumulation of missed opportunities for reallocation, thus representing past neglect more than current virtue.

The rest of the paper proceeds with further motivation of our comparative approach to analyzing productivity and reallocation in Section 2, providing a brief discussion of relevant models of industry dynamics, central planning, and the different economic reform programs adopted in the six countries. Section 3 discusses the data and methods for measuring productivity and decomposing productivity growth. Section 4 contains the results of our measurement of the magnitude of reallocation and its contribution to productivity growth. We also analyze the extent to which differences in the contribution of reallocation to productivity growth across time and countries are associated with the underlying factors of reallocation volume, productivity dispersion, and correlation between reallocation and productivity differentials. Section 5 contains a brief conclusion.

\section{Conceptual Framework}

Our approach to analyzing reallocation and productivity is motivated by standard theories industry dynamics with heterogeneous firms (e.g., Jovanovic, 1982; Hopenhayn, 1992; Hopenhayn and Rogerson, 1993; Ericson and Pakes, 1995). The key elements in these theories are costs of adjustment (entry, exit, investment, and factor changes), as well as uncertainty about the future evolution of productivity. ${ }^{3}$ A basic result from the theories is that firm turnover and reallocation occur even in stationary equilibrium. Of course, the data we are examining can hardly be considered as drawn from equilibrium environments, but the theories are nonetheless

\footnotetext{
${ }^{3}$ Exit costs arise through fixed costs of operating, including opportunity costs of staying in business rather than exiting the market.
} 
useful for understanding the association between productivity differences and firm dynamics and therefore reallocation-enhancing productivity.

Wrapping the models into a single framework, let us assume that profit-maximizing firms in a competitive industry have heterogeneous productivity given by $q=q(k, l ; f, a)$, where $q$ is a homogeneous output, $k$ is capital services, $l$ is labor services, $f$ is an idiosyncratic disturbance, and $a$ is an adjustment cost for factor changes continuing firms. In the context of the Jovanovic (1982) model, $f$ represents a signal of true productivity, about which firms gradually learn, while in Hopenhayn (1992), $f$ is a firm-specific shock with the distribution function $\mathrm{F}\left(f_{t+1} \mid f_{t}\right)$ strictly decreasing in $f_{t}$, so that future productivity tends to be increasing in current productivity. Entering firms pay sunk cost $C_{e}$ and receive an initial productivity draw from $G(f)$. Incumbents may choose to exit, paying $C_{x}$, which may be negative if the scrap value of the business exceeds the fixed cost of staying in the market. With the addition of an investment possibility, as in Ericson and Pakes (1995), a firm may try to improve its productivity by incurring cost $C_{I}$ to obtain a new distribution of productivity outcomes $F$ ' that stochastically dominates F. Finally, changes in factors ? $k$ and $? l$ incur an adjustment cost $a(? k, ? l)$, which reduces current period output (Hopenhayn and Rogerson, 1993). ${ }^{4}$

These assumptions yield predictions for relative productivity levels: both entrants and exiting firms should have lower average productivity than survivors. They also have implications for the pace of reallocation between continuing firms and through firm turnover (entry and exit), for the cutoff level of productivity for firms to continue operating, $f^{*}$, and for the effects of changes in costs on reallocation and productivity differentials. Increases in $C_{e}$ and $C_{x}$ tend to reduce entry, exit, $f^{*}$, and the mean $f$ of surviving firms. An increase in $C_{I}$ reduces productivity growth and reallocation, as firms are less likely to incur the higher cost, raise their productivity, and grow more than noninvestors. An increase in $a$ reduces reallocation among continuing firms but also acts like an increase in fixed costs of operating to increase exit, $f^{*}$, and the mean $f$ of survivors.

While the theoretical models contain a number of unrealistic assumptions - profit maximization, perfect competition, and homogeneous output, in addition to stationary equilibrium - it is nevertheless useful to investigate their implications in the settings we are studying. Concerning the socialist period, most variables that we think of as business decisions - output, product variety, prices, technology, wages, investment, exit, and entry-were either specifically planned or indirectly controlled. ${ }^{5}$ Enterprises had strong incentives to meet planned output targets, but little incentive to contain costs, to innovate, or to produce goods of value. There was no effective competition, and imports were tightly regulated. Worker mobility was restricted by a number of practices, and enterprises had little discretion in their decisions on employment. ${ }^{6}$ Sometimes employment levels were fixed explicitly, but the central planners' usual method of constraining employment, particularly in the later socialist period, was to set a maximum fund available for an enterprise's total wage bill while specifying a wage grid based on just a few criteria, such as occupation, industry, and seniority. There were also constraints on the ability of enterprises to fire workers, although layoffs were not completely unknown.

\footnotetext{
${ }^{4}$ The precise form of these adjustment costs (convex, linear, lumpy) is not the essential issue here, but see the discussion of cost structure in Hamermesh and Pfann (1996).

${ }^{5}$ Kornai (1992) provides a comprehensive overview of the socialist system and early reforms. The term "centrally planned" is a partial misnomer, because not every economic decision was centralized, but it is a standard label.

${ }^{6}$ For a discussion of labor allocation in the Soviet Union, see Granick (1987). Gregory and Collier (1988) discuss Soviet unemployment, which appears to have been very low (although non-zero).
} 
Effectively, all the adjustment costs discussed above would be extremely high, with $C_{e}$ and $C_{x}$ both close to infinite.

Conceivably, omnipotent and omniscient planners might have allocated resources to fulfill the plan's output and efficiency goals. But planning and implementation could also be influenced by political objectives, among them rapid industrialization and large, prestigious projects. Moreover, even the most efficiency-minded planners faced difficulties controlling all the enterprises in the economy. The greatest obstacle was posed by a lack of reliable information, which arose from inherent features of the system: fixed prices, ratchet effects, and other incentives that discouraged innovation and information revelation about productive capacities. Thus, while it seems unlikely that the planners would have been very successful in resource allocation and reallocation, how they actually performed is an empirical question-a very interesting one that we can address with our data.

The question is still more interesting in light of the variation in partial reforms adopted in the late socialist period. In Romania, no liberalization occurred until the Ceaucescus were overthrown at the end of 1989. By contrast, Hungary experienced a partial, gradual relaxation of the planning regime for the previous two decades under the rubric of "goulash communism," and decentralization of many economic decisions to the enterprise level accelerated from the mid1980s. Effectively, these reforms would have reduced costs of entry, exit, investment, and factor adjustment. The Soviet Union began perestroika reforms in late 1988, although these were much more tentative than the earlier ones in Hungary. Our data permit some analysis of the effects of these differences, particularly involving Hungary and Soviet Russia, on the pace of reallocation and its consequences for productivity growth.

The adoption of wide-ranging reforms during the transition period led to reductions in all types of adjustment costs, and the factors affecting reallocation and productivity begin to resemble those in market economies. Liberalization of decisions on prices, entry, exit, investment, employment, and scale of operation places these on the shoulders of enterprise owners and managers. These reforms together with privatization may increase incentives for productive reallocation through improved competition and corporate governance. Nevertheless, the size of adjustment costs is a function of factors such as the macroeconomic and business environment, and observers have frequently suggested that, despite rapid liberalization, continued government intervention during the transition may stifle reallocation. Direct subsidization and other forms of support for weak and failing enterprises may reduce fixed operating costs and impede exit, while discriminatory taxes, bureaucratic interference, poor contract enforcement, and uncertain property rights protection may raise entry and investment costs, thus hindering entrepreneurship and growth of more successful firms (e.g., Frye and Shleifer, 1997; Åslund, Boone, and Johnson, 1996). The transition economies could be subject to "sclerosis" (Caballero and Hammour, 1996), in which less productive resources remain employed due to market imperfections and government policies, while the creation of more productive matches of resources and enterprises is impeded.

The six countries we study in this paper cover the spectrum of transition policy strategies, at least as conventionally measured in evaluations of "progress" in reform and transition by international organizations such as the European Bank for Reconstruction and Development (EBRD) and the World Bank. The World Bank's (1996) four-group classification of 26 transition economies, for example, puts Hungary in the first group of leading reformers, Lithuania and Romania in the second group, Georgia and Russia in the third, and Ukraine in the fourth. Similarly, the EBRD's annual indicators of "progress in transition" invariably place 
Hungary at or close to the top of all transition economies; its average score across the price liberalization, foreign exchange and trade liberalization, small-scale privatization, large-scale privatization, enterprise reform, competition policy, banking sector reform, and non-banking sector financial institutions indicators has been the highest or close to it among all transition economies since 1994. The other countries started their major reforms later, implemented them more gradually, and have still not bridged the gap with Hungary. Georgia and Ukraine started most slowly, but they rapidly converged with Romania and Russia in the late 1990s. ${ }^{7}$

Regardless of the exact figures, which are certainly subject to measurement errors and disputes, the clearly different policies in the six countries suggests an interesting set of comparative hypotheses. During the socialist period, Hungary's partial reforms may have stimulated a somewhat faster paced and more effective productivity-enhancing reallocation compared to Soviet Russia. During the transition, if a quicker and more effective implementation of reforms tends to stimulate productivity-enhancing reallocation, then Hungary's ambitious policy is likely to be reflected in the fastest increase in the contribution of reallocation to productivity growth. ${ }^{8}$ Although productive reallocation may be slowest to emerge in Georgia, Russia, and Ukraine, it should tend to converge with that in Romania and Lithuania by the early 2000s. On the other hand, an alternative possibility suggested by the models of industry dynamics is that a reduction in adjustment costs may lead, at least over some range, to reduced contributions of reallocation to productivity growth. Lower costs of entry, for instance, will tend to lower the average productivity of entrants and raise the average of exiting firms relative to survivors, reducing the contributions to firm turnover. And lower costs of factor adjustment may lead to quicker responses that prevent large productivity gaps from developing. More generally, low adjustment costs may lead to low productivity dispersion, leaving little scope for reallocation to contribute to productivity growth. On the other hand, following liberalization, there may be an initial burst of productivity-enhancing reallocation, followed by a later period with relatively small direct contributions. Our empirical analysis provides evidence on these hypotheses.

\section{Data and Basic Methods}

\subsection{Sources, Samples, and Variables}

The paper uses annual census-type data for manufacturing firms in each of the six countries. ${ }^{9}$ Though the data sources and variables are similar, we have taken steps to make them sufficiently comparable to justify cross-country comparisons.

The basic sources for the Hungarian and Romanian data are balance sheets and income statements associated with tax reporting: to the National Tax Authority in Hungary and the

\footnotetext{
${ }^{7}$ Success in macroeconomic stabilization followed a similar pattern, with Hungary experiencing the smallest cumulative output decline before recovering (15 percent), followed by Romania ( 21 percent), Russia (40 percent), Lithuania (44 percent), Ukraine (59 percent), and Georgia (78 percent). Hungary never experienced annual inflation over 35 percent, while the other countries' inflation rates exceeded 100 percent in some years, and Georgia, Russia, and Ukraine's rates did not fall below that level until 1996 (World Bank, 2002).

${ }^{8}$ Bartelsman et al. (2004) suggest that the reallocation contribution to productivity growth is larger in transition countries implementing more institutional reform.

${ }^{9}$ The units of observation in these data are firms, except for multi-plant entities where individual plants are listed as "subsidiaries" (dochernye predpriyatiya or "daughter companies") in the Russian registries. Apparently most but not all cases of multiple plants are treated individually in Russia: the 1993 registry contains a variable indicating the number of plants, which equals 1 in 99.91 percent of the 18,121 nonmissing cases. To avoid double-counting, we have dropped the consolidated records of entities with subsidiaries from the analysis.
} 
Ministry of Finance in Romania. All legal entities engaged in double-sided bookkeeping report, with the exception of Hungary before 1992 - when only a sample consisting of all firms with at least 20 employees and some smaller firms is available. The Romanian data are supplemented by the National Institute for Statistics' enterprise registry and the State Ownership Fund's portfolio and transactions data. The Hungarian data are annual from 1986 to 2005, and the Romanian data span 1992 to 2006 . The database employment is similar to statistical yearbook numbers in both countries.

The other four countries are former Soviet Republics. Their data come from their national statistical offices, the descendants of the former State Statistical Committee (Goskomstat), and therefore tend to be quite similar to one another. The Georgian and Lithuanian data cover most firms outside the budgetary and financial sectors in 1995-2005 (Lithuania) or 2000-2004 (Georgia). The Georgian and Lithuanian databases include roughly three-fourths of total manufacturing employment reported in the yearbooks. We also use data from the 1989 Soviet industrial registry to get a measure of pre-transition productivity dispersion in the two republics. Unfortunately, we are unable to link these data with the later years, since our more recent data do not contain firm names or locations.

The main sources in Russia and Ukraine are industrial enterprise registries from their national statistical offices, supplemented by balance sheet data. The data span 1985-2004 for Russia, and 1989 and 1992-2006 for Ukraine. The Russian registries are supposed to include all industrial firms with over 100 employees as well as those that are more than 25 percent owned by the state and/or legal entities that are themselves included in the registry. In practice, it appears that once firms enter the registries, they continue to report even if these conditions no longer hold. The Russian data can therefore be taken as corresponding primarily to the "old" firm sector (and their successors) inherited from the Soviet period. The 1992-1996 Ukrainian registries contain all industrial firms producing at least one unit of output, where a unit is defined differently depending on the product. All legal entities outside the budgetary and financial sectors are included in the 1997-2006 registries. The pre-1992 Russian and 1989 Ukrainian data do not include firms in the military-industrial complex. The Ukrainian coverage is fairly complete except in 1989 (69 percent of employment). The Russian data cover nearly all activity through 1994; then the coverage declines to about 75 percent in more recent years as the de novo sector has grown.

Some truncation was necessary to make the samples comparable across countries. The data in all countries are limited to manufacturing (NACE 15-36). We exclude the tobacco industry (NACE 16) due to insufficient observations in four of the six countries and the recycling industry (NACE 37) because of noncomparability with the classification system used until recently in Russia and Ukraine. We also remove observations on variables showing highly volatile fluctuations from one year to the next if they meet any of the following criteria: increase (decrease) by a factor greater than five then decline (rise) by a factor greater than five, increase (decrease) by a factor greater than 10 in the year after entry, or decrease (increase) by a factor of 10 in the final year of observation. ${ }^{10}$

Following the previous literature on productivity growth decompositions, we analyze reallocation and productivity within industries, avoiding problems of comparisons across industries with very different technologies. Ideally one would prefer to use industries

\footnotetext{
${ }^{10}$ Outliers defined on the basis of labor and output are excluded from labor productivity calculations and those defined on the basis of capital as well are excluded from multifactor productivity exercises. Excluded observations constitute about 1 percent of the labor productivity sample and about 2 percent of the MFP sample.
} 
disaggregated to the level of product markets, so as to compare firms only to their competitors. On the other hand, since the productivity decompositions rely on deviations from the industry average, it is important to have sufficient numbers of firms in each sector to ensure reliable estimates. We have compromised by dividing manufacturing into 19 sectors, which are 2-digit NACE industries (except that 23 and 24 are combined, as are 30 and 32).

These data have been extensively cleaned to remove inconsistencies and to improve missing longitudinal linkages due to change of firm identifier from one year to the next (associated with reorganizations and changes of legal form, for instance). The inconsistencies were evaluated using information from multiple sources (including not only separate data providers, but also previous year information available in Romanian balance sheets and Russian and Ukrainian registries). The longitudinal linkages were improved using all available information, including industry, region, size, multiple sources for the same financial variables, and some exact linking variables (e.g., firm names and addresses in all countries except Georgia, Hungary, and Lithuania, where this information was not available) to match firms that exited the data in a given year with those that entered in the following year. For Hungary we also used a database with direct information on longitudinal linkages: if a firm changed its identification number for some reason (and it appeared in the data as a new entry or an exit), the database indicated whether it had a predecessor or successor and, if so, that firm's identification number.

To eliminate spurious exit and entry, we eliminated employment changes associated with disappearances followed by reappearances, as well as firm-years with more than 1,000 employees in the year of entry or exit. In Russia and Ukraine we also excluded firms in regions that are completely missing in the data in one of the two adjacent years, and those in industries with implausibly high entry or exit rates in that year (suggesting a change in sample coverage). ${ }^{11}$ Entry and exit associated with firms that were members of Soviet-era production associations or that belong to multi-establishment firms were also excluded in Russia. ${ }^{12}$

Summary statistics and definitions for employment, output, and capital stock are reported for the first and last years in each country's data in Table 1. Average employment significantly declines everywhere except Georgia. ${ }^{13}$ The particularly sharp declines in Hungary, Romania, and Ukraine can be explained by high rates of small firm entry after liberalization. ${ }^{14}$

\subsection{Productivity Measures and Decompositions}

We compute two types of firm-level productivity measures: labor productivity (LP) is calculated as the log of gross output or sales divided by number of employees, and multifactor productivity (MFP) is the residual from an industry-specific Cobb-Douglas production function of gross output (or sales) in capital and labor (using 19 manufacturing sectors). Both of these

\footnotetext{
${ }^{11}$ The size-related exclusions amount to no more than 0.3 percent of the sample in any country. The changes in industry and regional coverage result in the exclusion of about 2 percent of observations in Russia and Ukraine.

12 The reason for excluding production association entry and exit during the Soviet period and multi-establishment firm entry and exit during the transition period is that many of these firms report inconsistently in the data. In one year a consolidated entity may appear, in the next each of the establishments may report separately, or vice versa. These exclusion rules result in a conservative bias. Of course some production associations may be starting new establishments or closing others down, and there may be some true entry and exit in industries with implausibly high rates and in regions that enter and exit the dataset.

13 The Georgian data start only in 2000, and therefore do not exhibit a sharp decline. Georgia's average manufacturing employment in 1989 is much higher, at 302.

${ }^{14}$ Average employment and output decline among old firms (enterprises inherited from the socialist system) samples as well, but the Hungarian, Romanian, and Ukrainian declines are much smaller than in the full samples.
} 
measures have been used in previous studies of reallocation-enhancing productivity. Because they do not distinguish firm-level quantity and price variation, which are unavailable in the data, they also conflate technical efficiency and firm-specific price variation, thus representing revenue productivity. ${ }^{15}$ For our purposes, this is not necessarily a disadvantage, particularly if variation in firm-specific prices reflects quality differences. Moreover, if revenue productivity has lower dispersion than physical productivity (as found by Foster, Haltiwanger, and Syverson, 2008, for some U.S. industries), then our calculations of the productivity consequences of reallocation would be still larger if measured for physical productivity.

In each case, the productivity values are aggregated into a constructed productivity index for each year and industry, and then the aggregates are decomposed using methods that have become standard in the literature. We then further decompose the effect of reallocation on productivity growth into productivity dispersion, reallocation volume, and the correlation between reallocation and productivity differentials (described in detail in Section 4.3). It bears emphasis that the decomposition approach allows an examination only of direct contributions of reallocation to productivity growth, ignoring any indirect effects, for example entrants as a source of market pressures on incumbents.

The method of decomposing aggregate productivity growth employed here is a modified version of the proposal of Haltiwanger (1997) and Foster, Haltiwanger, and Krizan (2001), hereafter referred to as FHK. Construction of aggregate labor productivity measures involves summing firm-level measures to the aggregate level:

$$
P_{t}=\sum_{i} S_{i t} \sum_{e} S_{e i t} P_{e i t}
$$

where $P_{t}$ is aggregate productivity in year $t, S_{i t}$ is the employment share of industry/sector $i$ in year $t, S_{e i t}$ is the employment share of firm $e$ in industry $i$ and year $t$, and $P_{e i t}$ is the productivity of enterprise $e$ in sector $i$ in year $t$.

FHK's "method I" decomposition expresses the change in aggregate sectoral productivity over a period of length $k$ (thus from year $t-k$ to year $t$ ), $\Delta P_{i t}$ (where $P_{i t}=\sum_{e} S_{e i t} P_{e i t}$ ), as follows:

$$
\Delta P_{i t}=\sum_{e \in C} s_{e t-k} \Delta p_{e t}+\sum_{e \in C}\left(p_{e t-k}-P_{i t-k}\right) \Delta s_{e t}+\sum_{e \in C} \Delta p_{e t} \Delta s_{e t}+\sum_{e \in N} s_{e t}\left(p_{e t}-P_{i t-k}\right)-\sum_{e \in X} s_{e t-k}\left(p_{e t-k}-P_{i t-k}\right) .(2)
$$

The first term in (2) measures the average change in firm productivity holding composition constant at its base year $(t-k)$ structure, in order to distinguish average productivity growth from composition effects. This term may reflect firm restructuring and deterioration as well as mismeasured price and quality changes. The second term measures the between-firm (withinsector) reallocation effect, the covariance of share changes with the base year deviation of enterprise productivity from the industry mean. The third term measures the intrasectoral covariance of productivity and compositional changes, the "cross" effect, while the fourth and fifth represent the contributions of entry $(\mathrm{N})$ and exit $(\mathrm{X})$, respectively. ${ }^{16}$ The fourth and fifth

\footnotetext{
${ }^{15}$ See Eslava, Haltiwanger, Kugler, and Kugler (2001) and Foster, Haltiwanger, and Syverson (2008) for analyses of firm-specific revenue and physical productivity.

${ }^{16}$ We have also examined an FHK method using average period weights, which has the advantage of being more robust to measurement error but provides a less intuitive way to measure reallocation contributions; in any case, the results from that analysis produce similar qualitative conclusions. But we do not use the Olley and Pakes (1996) cross-sectional decomposition (OP) of aggregate productivity into unweighted average productivity and covariance of deviations of employment shares and productivity from sector means. The OP approach may attribute some
} 
terms combined are the net entry effect. We calculate the total reallocation contribution as the sum of the between and net entry effects. ${ }^{17}$

Notice, however, that the FHK net entry effect is not purely a reallocation effect. For instance, if exiting firms are just as productive on average as stayers in the initial period, and entrants are also equally productive as surviving incumbents in the final period, then the FHK net entry effect will simply be the entry share of activity multiplied by the change in sectoral productivity, i.e., its productivity growth contribution will be proportionate to its share of activity. The importance of this issue grows with the length of $k$. In our view, it is not very natural way to attribute a contribution to entrants that merely mimic the incumbents. An alternative approach is to compare entrants with the productivity of incumbents in year $t$ and to distinguish the aggregate productivity contribution of net entry due to above - or below-average productivity levels, relative to a benchmark in which exitors are like incumbents in the exit year and entrants are like incumbents in the entry year. This can be accomplished by decomposing FHK's entry term as follows:

$$
\sum_{e \in N} s_{e t}\left(p_{e t}-P_{i t-k}\right)=\sum_{e \in N} s_{e t}\left(P_{i t}-P_{i t-k}\right)+\sum_{e \in N} s_{e t}\left(p_{e t}-P_{i t}\right)
$$

The first term is the change in average sector productivity over the period, weighted by entrants' share, which may be labeled the "proportionate entry" term. The second term is the weighted average of entrants' productivity compared to the sector average in year $t$, the "disproportionate entry" term. ${ }^{18}$ The entire decomposition becomes:

$$
\begin{aligned}
& \Delta P_{i t}=\sum_{e \in C} s_{e t-k} \Delta p_{e t}+\sum_{e \in C}\left(p_{e t-k}-P_{i t-k}\right) \Delta s_{e t}+\sum_{e \in C} \Delta p_{e t} \Delta s_{e t}+\sum_{e \in N} s_{e t}\left(P_{i t}-P_{i t-k}\right)+\sum_{e \in N} s_{e t}\left(p_{e t}-P_{i t}\right) \\
& -\sum_{e \in X} s_{e t-1}\left(p_{e t-k}-P_{i t-k}\right) .
\end{aligned}
$$

The combination of exit and disproportionate entry show whether firm turnover contributes disproportionately to aggregate productivity growth. ${ }^{19}$ For comparison purposes when considering the results below, the FHK entry term can be recovered by simply adding the two entry terms in (4) together.

\footnotetext{
activities to within effects that the FHK decompositions treat as reallocation effects and vice versa. If two firms with fixed shares switch positions in the productivity distribution, OP reports a reallocation effect and FHK a within-firm effect from the change. When a firm above average size and productivity splits into two firms with the same productivity but below average size, this appears as a positive within effect and a negative reallocation effect with OP, but it has no effect on either the within effect or the reallocation effect in the FHK decompositions (the exit and entry terms cancel). OP treats exit of a firm below average in size and productivity as a positive within-firm and negative reallocation effect, while FHK treats the exit as a positive reallocation effect. In our view, the FHK accords more closely with intuition about reallocation.

${ }^{17}$ The cross term could partly be thought of as a reallocation contribution as well, though it is ambiguous how much of it is reallocation vsersus a within-firm effect.

${ }^{18}$ We thank John Haltiwanger for suggesting this terminology.

${ }^{19}$ Although they do not calculate the contribution of disproportionate entry as we do, Foster, Haltiwanger, and Krizan (2001) and Disney, Haskel, and Heden (2003) implicitly adopt the same perspective when they run regressions comparing the productivity of entrants in the final year to the productivity levels of exitors in the initial year and continuers in the initial and final years.
} 
Besides providing a more natural measure of the entry contribution, the equation (4) decomposition also has the advantage of shifting any measurement error in firm turnover into the proportionate entry term. If longitudinal links in the data are randomly broken so that some average-productivity continuers are counted as exits and subsequent entrants, for example, their relative productivity would contribute to the FHK entry term. In our modified decomposition, random breaks of firm linkages are incorporated into the proportionate entry term, but do not affect the exit and disproportionate entry terms. Moreover, since productivity of entering firms is compared with incumbents' productivity in the same year, the disproportionate entry term is not sensitive to mismeasured price deflators.

\section{Results}

\subsection{The Pace of Reallocation under Socialism and in Transition}

Before presenting the reallocation contribution decomposition results, we first report calculations of annual job reallocation measures following standard definitions (Davis and Haltiwanger, 1992). Figure 1 shows job creation, job destruction, job reallocation, and intraindustry excess job reallocation, and Appendix Table 1 contains the underlying data for these series plus the shares of entry and exit firm employment in total employment. Job creation and destruction among continuing firms can be calculated by subtracting these shares from total job creation and destruction, respectively. The difference between job creation and destruction is net employment change. The net change is negative in the early transition years in all countries, reflecting the sharp decline in the manufacturing sector during that period.

The pace of gross job flows under central planning, evidenced by the results from Hungary and Russia, are well below those typically found in market economies (which are typically 810 percent each for annual creation and destruction). However, the job flow rates during this period are significantly larger in Hungary than Russia. The higher rate in Hungary results from both higher creation and destruction among continuing firms and more firm turnover. Even though Hungary experiences only a modest amount of firm turnover prior to the transition, the Russian data show virtually none. These patterns may reflect greater pretransition reform in Hungary. Once the transition starts, there is a marked increase in job flows both from continuing firms and firm turnover. The increase is much larger in Hungary, which implemented faster reform.

Georgia experiences the largest creation and destruction rates on average during the transition. ${ }^{20}$ The rates in Hungary, Lithuania, and Romania are also quite high. Russia and Ukraine experience significantly less reallocation both from continuers and firm turnover. The high job destruction rates in Lithuania, Romania, Russia, and Ukraine are primarily a result of high continuing firm contraction, while exit also makes a large contribution in Georgia and Hungary. In contrast to the high levels of job destruction by continuing firms, job creation among these firms is subdued in the first few years of the transition everywhere. The subsequent rise in continuing firm job creation occurs near the time of economic recovery, which arrives first in Hungary, then Romania, Lithuania, Georgia, Russia, and finally Ukraine.

Coming just after the accumulated misallocations of central planning, the transition might have been expected first to bring about a temporary period of extraordinarily high job

\footnotetext{
${ }^{20}$ It is not possible to clean the longitudinal links in the Georgian data as thoroughly as in the other countries, since the data do not contain name or location information. The high Georgian firm turnover rates could at least partly reflect spurious exit and entry. But the job creation and destruction rates among incumbents are also highest in Georgia, so incomplete longitudinal links cannot be the full explanation.
} 
reallocation. Following this massive industrial restructuring, reallocation rates would then converge to developed economy norms. Such a pattern would be consistent with the discussion in Section 2, for instance, of the accumulated misallocation under central planning and the rapid liberalization reducing costs of entry and adjustment at the beginning of transition. For the most part, however, total job reallocation rates during the transition lie in the general range (15 to 30 percent) found in nontransition economies (e.g., Davis and Haltiwanger, 1999; p. 26). The main exceptions are Hungary from 1990 to 1993 and Georgia in 2001-02 and 2004, when job reallocation is much higher. More rapid firm turnover accounts for the faster reallocation only to some extent, and most of it is rather due to higher creation and destruction among continuing firms. With the exception of Hungary (the Georgian time series is too short to draw conclusions), it appears that liberalization did not produce a big burst of job reallocation after the negligible levels under socialism. Instead, job reallocation rates rose to developed economy levels and, with some fluctuations, have tended to stay within that range.

Finally, Figure 1d shows within-sector excess job reallocation rates, where sector refers to the 2-digit NACE industries described in Section 3 This type of reallocation is the most relevant for studying productivity growth decompositions, which we carry out within sectors, following the previous literature. Within-sector flows of jobs account for most job reallocation, generally 60 to 80 percent. This fraction is notably smaller than previous findings for other economies, where it is reported to lie in a range from 83 to 99 percent (Davis and Haltiwanger, 1999; p. 2726). The transition appears to have raised between-sector reallocation disproportionately. Nevertheless, the within-sector flows are still much harger, and they are the focus of the productivity analysis to which we turn next.

\subsection{Productivity Decompositions}

It is useful to start by reviewing long-run FHK results for the U.K. and U.S., as developed economy benchmarks. Based on LP, the U.K. and U.S. between-continuing firm contributions are small (2.81 and 1.84 percentage points, respectively), and it is actually negative with U.S. MFP (-0.82). The FHK net entry terms (the sum of proportionate entry, disproportionate entry, and exit) are sizeable, which has been interpreted to suggest that firm turnover is an important contributor to their productivity growth. The proportionate entry effect accounts for 73-86 percent of the FHK net entry term, however. We calculate that exit and disproportionate entry contribute 4.91 and 1.84 percentage points to LP growth in the U.K. and U.S., respectively, or 7-8 percent of aggregate LP growth over the period. For MFP growth, the firm turnover contribution is even smaller: 1.61 and 0.51 percentage points in the U.K. and U.S. The total reallocation contribution (between, disproportionate entry, and exit) to MFP growth is actually negative for the U.S. These results suggest that productivity growth directly attributable to reallocation is quite modest in the U.K. and U.S., consistent with the presence of low entry barriers and high exit thresholds. ${ }^{21}$

Table 2 also shows long-run productivity decompositions for Hungary, Lithuania, Romania, Russia, and Ukraine. Total growth is substantial in Hungary, Romania, and Ukraine, while Russia's is relatively small for MFP and slightly negative for LP. ${ }^{22}$ The within effects are

\footnotetext{
${ }^{21}$ It is important to re -iterate that reallocation could also contribute indirectly, as entrants and expanding incumbents could discipline other incumbents to increase productivity or exit.

${ }^{22}$ Note that the totals for the transition countries are averages across sectors using initial-year weights. The LP growth when applying final-year weights to finalyear productivity is 62.92 percent in Hungary, 102.82 percent in Lithuania, 59.78 percent in Romania, 9.41 percent in Russia, and 70.75 percent in Ukraine, implying that
} 
large and positive in Hungary, Lithuania, Romania, and also for Ukrainian LP, but negative in Russia and for Ukrainian MFP. Hungary's between terms are negative, while Lithuania, Romania, Russia, and Ukraine's are positive and much larger than in the U.K. and U.S. The negative cross terms for Hungary, Lithuania, and Romania suggest that firms with growing productivity have falling employment shares. ${ }^{23}$ In contrast, within-firm productivity growth is strongly positively associated with employment share change in Ukraine. Disproportionate entry is negative in Hungary and Romania, as well as with Lithuanian and Russian LP, and positive in Ukraine and with Lithuanian and Russian MFP. Exit is positive everywhere, so the exitors had below-average productivity. The FHK net entry terms are largest in Hungary, Lithuania, and Romania, followed by Ukraine, with Russia trailing far behind. That ordering is consistent with economists' observations that Eastern European growth has been driven by new firm entry to a much greater extent than the former Soviet Union. ${ }^{24}$ But if the proportionate entry term is removed, net entry actually contributes negatively to Hungary and Romanian LP growth, while the contribution is still quite positive in Russia and Ukraine. The total reallocation contribution (not including proportionate entry) is largest in Ukraine, followed by Russia, Lithuania, Romania, and Hungary, in inverse order of reform progress. Except in Hungary and for Romanian LP, these contributions are larger than in both the U.K. and U.S. These patterns may reflect higher entry barriers and lower exit thresholds in the less advanced reformers.

Was reallocation productivity-enhancing under central planning? Was Hungary's reallocation productivity enhancing in the early reform period, but did it become less so as reform progressed? To address these and other questions about the dynamics of the productivity growth process, we show three-year LP decompositions in all six of our transition economies in Figure $2 b$ (and Appendix Table 2). Each dot in the figures represents the particular effect for the three-year period ending in the year on the $\mathrm{X}$ axis.

Total growth and the within-continuing-firm contribution follow a "J-curve" pattern in each country with a long time series. ${ }^{25}$ Hungary's decline begins earlier than in Russia and Ukraine, but its trough is much shallower, and the recovery begins several years earlier. While the within-firm contribution is the source of nearly all Hungary's productivity growth, it is important but not dominant elsewhere. Growth in Georgia, Lithuania, Russia, and Ukraine after Russia's 1998 financial crisis is impressive. ${ }^{26}$

intersectoral reallocation has contributed positively in Hungary, Russia, and Ukraine and negatively in Lithuania and Romania. MFP growth when using output weights (as with the U.S. MFP decomposition) is 64.71 percent in Hungary, 111.51 percent in Lithuania, 132.38 percent in Romania, 22.41 percent in Russia, and 89.65 percent in Ukraine. As robustness checks, we have calculated the Russian totals using aggregate deflators rather than disaggregated ones, as well as different outlier exclusion rules, and the results are very similar. The lower overall growth in Russia is not driven by any one sector, as nine of the nineteen Russian sectors exhibit negative total LP growth and seven have negative MFP growth.

${ }^{23}$ Measurement error can also negatively bias the cross term. See Foster, Haltiwanger, and Krizan (2001) for a discussion.

${ }^{24}$ See, for example, World Bank (2002).

${ }^{25}$ The within, cross, and proportionate entry terms in this decomposition should be treated with caution, because any measurement error in price changes (associated for instance with quality differences or high and volatile inflation) is reflected directly in these components. During the socialist period, repressed inflation is not reflected in the figures, nor are improvements in the quality and availability of goods during the early transition; in the former case the within term is overstated, and in the latter it is understated. The reallocation terms do not suffer from the same measurement error problems to the extent that these errors are common across fir ms within an industry-period cell.

${ }^{26}$ The higher productivity growth in Georgia and Ukraine compared to Russia in the 2000 s is consistent with those countries' official yearbook real production growth and employment series, which show average production growth 
The cross term is nearly always negative in Hungary and Romania, consistent with the long-run decomposition. The cross term changes signs in Russia and Ukraine, however: in the early transition firms with growing productivity downsize less, but in later years they contract more.

The proportionate entry term and the FHK entry term are very large and negative, then large and positive in the early years of Hungary's transition. These massive swings surely reflect a large volume of entry during a time when within-firm productivity growth is highly volatile rather than changes in the quality of entrepreneurship. The term is relatively unimportant in Hungary in later years and in the other countries, with the exception of Georgia and Ukraine in the 2000's, where it is significantly positive. ${ }^{27}$

The contribution of reallocation to productivity growth during the central planning period is virtually zero. Reallocation contributes much more once the transition starts, rising from 0.52 in 1987-90 to 11.75 percentage points of growth in 1992-1995 in Hungary, -0.74 in 1989-92 to 5.33 in 1992-95 in Russia, and 0.57 in $1989-92$ to 2.75 in 1992-95 in Ukraine. The bulk of the gain comes from continuing firm reallocation.

In Hungary, the reallocation contribution to productivity growth peaks in 1992-95, when it is the highest among the countries observed in that period. After 1994-97, the contribution of reallocation in Hungary never surpasses 6 percentage points. Though Hungary has large contributions from between reallocation and exit in most years, its total reallocation contribution is brought down by a negative disproportionate entry term. Not only is the disproportionate entry contribution negative, but the sum of exit and disproportionate entry is also negative. This holds true for Romania as well.

By the late 1990s, the reallocation contribution rises to double-digit levels in Russia and Ukraine. Continuing firm reallocation and exit contribute roughly equally to the rise in Russia, while more of it comes from continuing firm reallocation in Ukraine. Georgia has the highest reallocation contribution (45.33 percentage points in 2000-03), and its between and exit terms are both large. This shows that the productivity boom in these countries since Russia's 1998 financial crisis has not come simply from a restoration of incumbent firms' pre-transition production levels. Lithuania and Romania also show significant reallocation contributions, but only via continuing firm reallocation, and their levels are below those in Georgia, Russia, and Ukraine. The high between terms in Georgia and Ukraine in particular are symptomatic of exit barriers for unproductive firms. The fact that the exit terms begin to rise much later than the between terms, except in Hungary, is also consistent with there being exit barriers in the early transition in the slower reformers.

These substantial cross-country differences are due neither to variation in industrial composition, as discussed further in the next section, nor to differences in coverage of the small enterprise sector (which may be lower in the Georgian, Lithuanian, and Russian registries compared to the other countries). As a check on whether the latter consideration influences the results, Appendix Figure 1 shows the total reallocation contribution from three-year LP decompositions with samples where employment of 100 or below is set to missing, entry is defined as the first year a firm has more than 100 employees, and exit is defined as the year after the last year the firm has more than 100 employees. The results are very similar to the ones including all employment levels in Figure 2g.

between 2000 and 2004 of 12.4 percent in Georgia, 6.0 percent in Russia, and 14.7 percent in Ukraine, and employment growth of -10.4 percent in Georgia, -9.9 percent in Russia, and -11.7 percent in Ukraine.

${ }^{27}$ Proportionate entry is larger in longer-term decompositions, as the entrant share is higher. 
The entry contributions deserve closer examination. Note that the disproportionate entry terms in Figure $2 f$ pool entrants from two years prior to the end year of the decomposition, a year before the end year, and the end year. Many of the end-year entrants are likely to be unproductive, and once they discover that, they will need to either learn how to become productive or exit. The disproportionate entry terms may thus be weighted down by the end-year cohort. We thus show disproportionate entry terms for each cohort separately in Figure 3 and Appendix Table 6. Older cohorts contribute more positively to productivity growth than fresh entrants. If the current-year entrants were removed, the vast majority of the net entry terms would be positive, including 14 of 17 of Hungary's. To measure the disproportionate contribution of entrant learning and selection to productivity growth within a two-year period, we calculate the difference between the two-year-old entrant contribution and their contribution as new entrants two years earlier in Figure $3 \mathrm{~d}$. This difference is nearly always positive, suggesting that productivity-enhancing learning and selection has made a disproportionate contribution (i.e., above trend growth for the sector) to productivity growth. The effect has been stronger in Romania and especially Hungary than in Russia and Ukraine. Russian and Ukrainian entrants start out with similar productivity to incumbents, and this doesn't change much as they age, while Hungarian and Romanian entrants are initially quite unproductive on average, but the survivors among them are as productive as incumbents a year or two later. This suggests that Russia and Ukraine have higher entry barriers, while Hungary and Romania have more entrepreneurial experimentation, learning, and selection. Though not displayed here, we have also calculated separate disproportionate entry terms for the longer-run decompositions, and even most older Hungarian cohorts perform only about as well as incumbents, and their contributions generally lag those of similarly-aged Russian and Ukrainian cohorts. Hungary's entrant performance is similar to that in the U.K. - results in Disney et al. (2000) show that only one entry cohort's productivity is higher than that of incumbents in the final year of its 1980-1992 decomposition. These results imply stronger age-productivity correlations in more advanced economies.

We measure the extent to which entry cohorts catch up to incumbents via learning vs. selection by calculating two-year labor productivity decompositions for each entry cohort, where entrant labor productivity is deviated from the contemporaneous industry level. The within-firm productivity growth term is the learning, and selection is the between and exit terms. Figure 4 shows the averages among all entry cohorts since the transition began that are available in our data. The selection contributions are quite similar across countries, while learning is much greater in Hungary and Romania both relative to their selection contributions and compared to the learning terms in the other countries. Learning is less important than selection in Russia and especially Ukraine. These results are consistent with the presence of lower costs of investment in the more advanced reformers (investment facilitates learning).

In appendix tables we show five-year LP and three- and five-year MFP compositions. The cross-country and cross-time patterns are similar to those in the three-year LP decompositions. The disproportionate entry terms are higher and the exit terms are lower for MFP than LP, suggesting lower entrant and higher exitor capital intensity. Net entry is larger with MFP. The U.K. and U.S. five-year MFP total reallocation contributions are negative.

To summarize the results in this subsection, the rise in the reallocation contribution in the transition period relative to the socialist period is consistent with the hypothesis that market institutions facilitate productivity-enhancing reallocation, but the larger reallocation contributions in Georgia, Russia, and Ukraine compared to Lithuania, Romania, and especially 
Hungary, the U.K., and the U.S. is not. The timing of the rise in the reallocation contribution shows an initial burst followed by decline only in Hungary, but the burst is short-lived, peaking in the early 1990s and essentially disappearing after about 2000. In the other countries, we observe a steadier rise to levels that remain high and exceed the Hungarian peak in Russia, Ukraine, and Georgia. Moreover, it is striking that even older entry cohorts in Hungary, Romania, and Lithuania do not contribute positively to productivity growth, and generally less than in Georgia, Russia, and Ukraine. Do Georgia, Russia, and Ukraine's larger reallocation contributions come as a result of employment adjustments at a slower, more "optimal" speed? The next section provides a deeper investigation into cross-country differences in the reallocation contribution.

\subsection{Analyzing Differences in Productivity-Enhancing Reallocation}

What factors lead to higher contributions of reallocation to productivity growth? We focus on three fundamental conditions: the volume of reallocation, the dispersion of productivity, and the correlation of reallocation and productivity differentials. We decompose the total contribution of reallocation, defined as the sum of the between, disproportionate entry, and exit terms in equation (4), into these three terms, measured as the standard deviation of employment share changes, the standard deviation of productivity, and correlation between share change and relative productivity. The difference in the reallocation contribution between sectors (or countries or time periods) $i$ and $j$ can be decomposed in the following way:

$$
\begin{aligned}
& \sum_{e}\left(p_{e t-k}-P_{i t-k}\right) \Delta s_{e t}-\sum_{f}\left(p_{f t-k}-P_{j t-k}\right) \Delta s_{f t}= \\
& .5 \times\left\{\operatorname{Corr}\left(\Delta s_{e t}, p_{e t-k}-P_{i t-k}\right)+\operatorname{Corr}\left(\Delta s_{f t}, p_{f t-k}-P_{j t-k}\right)\right\} \times\left[.5 \times\left\{N_{i} \sigma_{\Delta s_{t}}+N_{j} \sigma_{\Delta s_{f t}} \int \sigma_{p_{t-k}-P_{t-k}}-\sigma_{p_{f t-k}-P_{s t-k}}\right\}\right] \\
& + \\
& .5 \times\left\{\operatorname{Corr}\left(\Delta s_{e t}, p_{e t-k}-P_{i t-k}\right)+\operatorname{Corr}\left(\Delta s_{f t}, p_{f t-k}-P_{j t-k}\right)\right\} \times\left\lfloor .5 \times\left\{\sigma_{p_{e t-k}-P_{t-k}}+\sigma_{p_{f t-k}-P_{j t-k}}\right\} \times\left\{N_{i} \sigma_{\Delta s_{a t}}-N_{j} \sigma_{\Delta s_{f t}}\right\}+\right. \\
& .5 \times\left\{N_{i} \sigma_{\Delta s_{e t}} \sigma_{p_{e t-k}-P_{i t-k}}+N_{j} \sigma_{\Delta s_{f t}} \sigma_{p_{f t-k}-P_{j t-k}}\right\} \times\left\{\operatorname{Corr}\left(\Delta s_{e t}, p_{e t-k}-P_{i t-k}\right)-\operatorname{Corr}\left(\Delta s_{f t}, p_{f t-k}-P_{j t-k}\right)\right\}
\end{aligned}
$$

The first term in this equation is the productivity dispersion component. Gaps in productivity across firms create the potential for productivity-enhancing reallocation - without these gaps, reallocation can have no productivity effect. Productivity dispersion can thus be considered a measure of "cleansing potential." The employment share change dispersion component is the second term. Ceteris paribus, the more reallocation occurs across firms, the more it can affect productivity growth. This can be thought of as reallocation intensity or volume. The third term is the reallocation-productivity correlation component. A positive correlation is essential for reallocation to be productivity-enhancing. The stronger the correlation, the more precise is the targeting of reallocation from less productive toward more productive firms. We first analyze each of the components, focused on the case of three-year periods and labor productivity, and then we report the results from decomposition (5).

One would expect productivity dspersion to display an inverse U-shaped pattern as a function of market reform. An abrupt shift in prices and markets may be advantageous for some firms but disadvantageous for others. Firms are unlikely to adapt equally well to the new market environment. New firms will enter and experiment, some with high and others with low productivity; as they learn a selection process will tend to make them more homogenous. Exit will also reduce heterogeneity, but weaker firms may be allowed to survive in countries 
implementing only partial reform, while they are pushed out with more complete reform. Together, these forces imply an inverse- $U$ shaped profile. Figure 5a presents the standard deviation of labor productivity using initial year productivity (except for entrants, whose productivity is measured in the final year (three years later in this three-year decomposition case) $){ }^{28}$ Productivity dispersion is very similar across the five countries where we can measure it on the eve of the transition, as well as to the United Kingdom. ${ }^{29}$ It rises by 60-240 percent after the introduction of reform, then plateaus. The fact that it plateaus suggests that cleansing of less productive firms is sufficient to prevent a further increase in dispersion, but not enough to bring it down to levels found in developed market economies. It both increases and plateaus earliest in Hungary and latest in Ukraine. In the later transition heterogeneity is highest in Ukraine, followed by Georgia, Lithuania, Russia, Romania, and Hungary, roughly in inverse order of reform progress in the early transition.

This massive productivity dispersion increase could simply be an uncovering of preexisting gaps between firms that were hidden due to features of central planning such as fixed input and output prices and absence of competition. Alternatively, the physical and human capital needed to perform well in centrally planned and market systems may be very different. The former would suggest little change in firms' relative productivity rankings and the latter substantial change. To investigate this we calculate the correlation between the productivity ranks of continuing firms across three-year periods. Figure $5 \mathrm{~b}$ shows one minus this correlation. Prior to the transition, firm ranks change very little, though more in Hungary than Russia (perhaps reflecting the partial reform process in Hungary). A large amount of rank change occurs at the beginning of the transition, then the pace falls somewhat. Romania's rank change is usually highest, followed closely by Lithuania and Georgia, while Hungary, Russia, and Ukraine's are somewhat lower during the later years. The large increase in rank change coincides with the rise in productivity dispersion, suggesting that the greater dispersion is not just an uncovering of inherited gaps.

Similar to the analysis job reallocation in Section 4.1 are the results in Figure $5 c$ for the standard deviation of employment share changes across three-year periods (multiplied by the number of firms appearing in one or both years). Within-sector reallocation increases dramatically with reform in Hungary, but much more gradually in Russia and Ukraine. During the later years Georgia, Hungary, and Romania have the highest volumes, about twice as large as in Russia.

Privatization and improved corporate governance should reorient firms toward profit maximization, implying that successful firms should strive to increase market share and unsuccessful ones should contract. Competition should also force the weaker firms to contract and exit. These factors would suggest that targeting of reallocation should improve with market reform. On the other hand, high reallocation volume sparked by reform could result in weaker average targeting. The employment share change-productivity correlation across three-year periods is displayed in Figure 5d. The Russian and Hungarian correlations fall in the early transition compared to the late central planning period. Their correlations then rise, as does Ukraine's. Russia and Ukraine's improvements in targeting are much greater than Hungary's, however. Reallocation in Russia, Ukraine, and Georgia has been quite well targeted in recent

\footnotetext{
${ }^{28}$ Appendix Table 7 shows the numbers behind Figures 4 and 5a-5c.

${ }^{29}$ Disney et al. (2003) report labor productivity variance of 0.44 in the United Kingdom manufacturing sector in 1992, which translates into a standard deviation of 0.66 .
} 
years, and Lithuania and Romania's reallocation is also targeted more toward productive firms. In contrast, Hungary's reallocation-productivity correlation has hovered around zero.

We next analyze the extent to which the three components account for differences between the reallocation contributions across countries in the early transition (1992-1995) in Table 3a. As with the productivity growth decompositions, the results are averages over the 19 sectors, weighted by employment. Here the employment shares are those of the second country listed. A fourth term, industry share effect, is the residual between the actual difference in reallocation contributions using each country's own weights and the difference when using the second-listed country's weights for both countries. Hungary's higher reallocation contribution in the early transition compared to the other countries can be explained mainly by its higher reallocation volume, but also to some extent by having higher productivity dispersion than Russia and Ukraine. Hungary's reallocation contribution would have been over four percentage points higher had its targeting of the reallocation been as good as in Romania, Russia, and Ukraine.

Decompositions of the differences in reallocation contributions across countries in the most recent period are shown in Table 3b. Hungary's fall from having the highest to the lowest reallocation contribution to productivity growth can be accounted for by a reduction in the size of the gap between Hungary's reallocation volume and that of the other countries, higher productivity dispersion in the other countries, and especially by much better targeting of reallocation in the direction of more productive firms elsewhere. More precise targeting leads to 7-42 percentage points higher reallocation contributions in the other countries relative to Hungary. Romania has a higher reallocation contribution than Lithuania mainly due to higher reallocation volume, while Georgia, Russia, and Ukraine have higher contributions due to better targeting. The lower reallocation contribution in Romania relative to Georgia, Russia, and Ukraine follows a similar pattern to Hungary's, where Romanian reallocation volume is higher, but productivity dispersion is lower, and targeting is much worse. Russia's contribution is lower than in Georgia and Ukraine mainly because of lower Russian reallocation volume and productivity dispersion.

The components of the reallocation effect may be interrelated. High productivity dispersion could facilitate the targeting of reallocation (entrepreneurs will have better information about whether they should increase or decrease market share) and may encourage a higher volume of reallocation, since reallocation gains are higher. Good targeting and high reallocation volume can lower productivity dispersion (the less productive firms downsize and exit). High reallocation volume may hinder targeting and produce higher productivity dispersion, which would be consistent with the optimal speed of transition hypothesis and hyperkinesis.

We test whether such associations exist in the data in regression analysis shown in Table 4. The regressions exploit variation within industries and countries across time. The observations are industry-country-year cells for modified versions of components of the reallocation contribution to three-year labor productivity growth. ${ }^{30}$ Industry, country, and year

\footnotetext{
${ }^{30}$ Note that the initial incumbent productivity dispersion measure here is not the same as the productivity dispersion measure which is a component of the reallocation contribution, as subsequent entrants are excluded from initial incumbent productivity dispersion. Including entrants in initial productivity dispersion could introduce a simultaneity problem, as employment share change dispersion will be higher if entry is higher, and higher entry is likely associated with greater productivity dispersion among the entrants. The productivity dispersion change regressions do not include entrants in either the dependent or independent variables, as the focus here is on the
} 
effects are included as controls. The first column shows that initial incumbent productivity dispersion is associated with significantly higher reallocation volume. The coefficient implies that moving from Ukraine's incumbent productivity dispersion in 1989 to that in 1999 would yield 99.6 percent higher employment share change dispersion, which is close to the same amount that Ukraine's employment share change dispersion actually increased during the period. As shown in column 2, initial incumbent productivity dispersion is associated with better targeting of reallocation toward more productive firms. According to the coefficient, moving from Ukraine's incumbent productivity dispersion in 1989 to that in 1999 results in 0.076 higher correlation between employment share change and productivity, which is nearly as much as Ukraine's correlation increased in reality. Change in incumbent productivity dispersion can be thought of as a measure of the amount of cleansing within the group: if less productive firms exit, then productivity dispersion should fall. The regression in column 3 tests whether incumbents' reallocation volume and targeting reduce their productivity dispersion. Both are negatively associated with reduced incumbent productivity dispersion, though targeting is not quite statistically significant. Increasing Ukraine's reallocation volume among incumbents in 2002-2005 to that in Hungary at he same time would yield a 0.020 drop in productivity dispersion. Replacing Hungary's incumbent share change-productivity correlation in 2002-2005 with that of Ukraine would reduce incumbent productivity dispersion by 0.010 . This suggests that it would take many years of reallocation volume at Hungary's rate and Ukraine's precision for Ukraine's productivity dispersion to fall to Hungary's level (Ukraine's productivity dispersion in 2005 among firms producing since 2002 is 0.48 higher than Hungary's). Column four, which includes a squared term for reallocation volume, suggests that there are diminishing returns for reallocation volume to reduce productivity dispersion. None of the countries are in the range where the marginal effect of reallocation volume on productivity dispersion change is positive, however, so hyperkinesis appears not to be a major factor.

\section{Conclusion}

This paper measures the contribution of employment reallocation to aggregate productivity growth using manufacturing census data in Georgia, Hungary, Lithuania, Romania, Russia, and Ukraine. Reallocation contributes negligibly to productivity growth during the socialist period, although more in partially reformed Hungary than centrally planned Soviet Russia. After reform, reallocation contributes much more than previously reported for the United Kingdom and United States. In Hungary, the fastest reformer in this group, the magnitude of the contribution is high in the early transition years, but then declines to nearly zero by the late 1990s. In Ukraine and Russia, the slowest reformers, he contribution is relatively low initially and grows significantly as the transition progresses, reaching very high levels by international standards in both these countries and Georgia. In Romania and Lithuania, the intermediate reformers, the situation is also intermediate, with moderate rises in the contribution that tend to be sustained. In all countries, reallocation between continuing firms is strongly productivity-enhancing, but firm turnover is productivity-enhancing only in Georgia, Russia, Ukraine, and sometimes Lithuania.

The patterns of differences across countries and over time are not due to differences in data definitions, samples, and procedures, nor to decomposition methods, productivity measurement, or industrial composition. They appear to be robust along all these dimensions.

cleansing process among incumbents, not entrants. Again, greater entry (and thus reallocation volume when including entry) is likely to lead to temporarily higher productivity dispersion, 
However, they are not fully consistent with the standard presumption that reform increases productivity-enhancing reallocation. Reallocation has become more productivity-enhancing since the transition began, and Russia and Ukraine's reallocation contributions have increased as more reform has ben implemented. But the hypothesis doesn't explain why more gradually reforming Georgia, Russia, and Ukraine have experienced reallocation contributions so much higher than faster reforming Hungary, Lithuania, and Romania's. The relationship between reform and productivity-enhancing reallocation thus appears to be inverse U-shaped. The results do not support the optimal speed of transition hypothesis or the presence of hyperkinesis either, as Russian and Ukrainian reallocation volume and its contribution to productivity increase in tandem, and Georgia's reallocation volume is also both high and productivity-enhancing.

What then can explain why the reallocation contribution is higher in the slower reformers? As reform is introduced, firms face a new environment; some adapt better than others, creating productivity gaps. High inflation, lingering price controls, and state subsidies distort market signals, making it hard for the economy to channel reallocation toward more productive firms. $^{31}$ The longer an economy remains in a state of incomplete liberalization and stabilization, the more productivity dispersion rises, resulting in greater and greater potential for cleansing. Slower initial reallocation volume leads to a later high contribution to productivity not because slower reallocation creates better matches, but rather because the slow pace of reallocation allows productivity gaps to widen. In contrast to the transition economies, the U.K. and U.S. economies may have been continually swept clean of ess productive firms, reducing the scope for reallocation to contribute to productivity growth. Our regression results are consistent with this story: incumbent productivity dispersion tends to raise reallocation volume and the quality of targeting, while higher reallocation volume and better targeting tend to reduce incumbent productivity dispersion.

Contrary to the expectations of some economists, we find that the measured contribution of entry to productivity growth is initially negative, particularly in the advanced reformers. The more advanced economies' lower entry and exit barriers are associated with greater experimentation: more low-productivity firms enter, pulling down the entry contribution to productivity growth. The learning and selection process among the new entrants is more intensive in advanced reformers, though, so the surviving entrants achieve similar productivity levels as surviving incumbents within a year or two. The entry contribution in advanced reformers is also diminished by the fact that within-firm productivity growth among surviving advanced-reform-country incumbents is substantially higher on average during the transition as a whole, so catching up to surviving incumbents is a greater achievement under these circumstances.

An important lesson emerging from this analysis is that a large level of direct productivity-enhancing reallocation is a second-best outcome. It would have been better if some firms had not had such difficulty adapting to the new market environment and experienced precipitous productivity drops, or if they had exited before falling so far behind. Indeed, the relationship between reform and the within-firm productivity contribution appears to be $U$ shaped - Hungary, for example, has experienced higher overall productivity growth during the transition than the other countries, and most of it was achieved through within-firm productivity

\footnotetext{
${ }^{31}$ Inflation and price controls make it difficult for firms to sort out whether they will be more or less productive than their competitors as prices change. State subsidies encourage less productive firms to stay in the market.
} 
growth. ${ }^{32}$ Given that the productivity gaps have formed, though, the slower reformers would be much worse off if the reallocation they have experienced had been blocked. The continued presence of these gaps suggests that the potential exists for much more reallocation-induced productivity growth well into the future.

We argue that the conventional measures of the contributions of entry and net entry of previous studies are difficult to interpret, since they are highly sensitive to the share of new entrants and trend productivity growth. We address this problem by decomposing the standard entry term into proportionate and disproportionate entry, and the latter is useful for evaluating entry's contribution. At face value, the standard entry term suggests that entry is an important source of productivity growth in the U.K. and U.S., and that it is more important in Hungary and Romania than in Ukraine or Russia. But the results from the decomposition into proportionate and disproportionate entry show that entrants' productivity is actually lower on average than that of surviving incumbents in several of the countries, particularly when using shorter decomposition periods. By calculating separate disproportionate entry terms for each entry cohort within the decomposition period, we show that the terms for disproportionate entry of all cohorts together are dragged down by the most recent cohorts. Older cohorts tend not to make negative contributions to productivity growth. Through following a cohort's contribution to productivity growth across time, we are able to measure the contribution of entrant learning and selection to productivity growth. Our analysis shows that the higher Russian and Ukrainian overall disproportionate entry contributions are due to initial productivity levels that are similar to those of incumbents, but more intensive learning and selection processes in Hungary and Romania enable entrants, whose initial productivity falls significantly short of incumbents, to catch up within two years. This stark contrast may reflect differences in entry costs associated with the business environment in the former Soviet versus the EU member states.

We decompose the total reallocation contribution to productivity into productivity dispersion (cleansing potential), reallocation volume, and targeting of the reallocation toward more productive firms. The decomposition analysis illustrates how productivity-enhancing reallocation is not simply a matter of having high reallocation volume. Despite their significantly lower volume, Georgia, Russia, and Ukraine have had much higher reallocation contributions to productivity growth than Hungary, Lithuania, and Romania because of larger productivity gaps and much better targeting. Finally, we take advantage of within-industry variation across time to identify relationships among the different components of productivityenhancing reallocation, which provides support for the hypothesis that productivity dispersion encourages reallocation volume and facilitates targeting, while volume and targeting reduce dispersion.

We have found that the transition economy reforms and recessions were characterized by highly idiosyncratic shocks across firms, which can help explain the rise in productivityenhancing reallocation. It would be useful to conduct this analysis in other economies to see if it is more generally true. Our reallocation contribution decomposition could also help explain differences in the contribution of productivity-enhancing reallocation to productivity growth across time, sectors, regions, and countries. One might expect variation in technologies and institutions (e.g., labor market and corporate governance institutions) to lead to differences in productivity dispersion, reallocation volume, and the quality of reallocation targeting.

\footnotetext{
${ }^{32}$ If firms with lower productivity growth or with less potential for future productivity growth exit, the firms that remain will have higher average within-firm productivity growth, which could help explain Hungary's superior within -firm productivity growth.
} 


\section{References}

Åslund, Anders, Peter Boone, and Simon Johnson, "How to Stabilize: Lessons from PostCommunist Countries." Brookings Papers on Economic Activity, 217-291, 1996.

Aw, Bee Yan, Xiaomin Chen, and Mark J. Roberts, "Firm-Level Evidence on Productivity Differentials and Turnover in Taiwanese Manufacturing." Journal of Development Economics, Vol. 66(1), 51-86, October 2001.

Baily, Martin Neil, Charles Hulten, and David Campbell, "Productivity Dynamics in Manufacturing Plants." Brookings Papers on Economic Activity: Microeconomics, 187-249, 1992.

Bartelsman, Eric, John Haltiwanger, and Stefano Scarpetta, "Microeconomic Evidence of Creative Destruction in Industrial and Developing Countries." IZA Working Paper No. 1374, October 2004.

Boeri, Tito, and Katherine Terrell, "Institutional Determinants of Labor Reallocation in Transition.” Journal of Economic Perspectives, Vol. 16(1), 51-76, Winter 2002.

Brown, J. David, and John S. Earle, "Gross Job Flows in Russian Industry Before and After Reforms: Has Destruction Become More Creative?" Journal of Comparative Economics, Vol. 30(1), 96-133, March 2002.

Brown, J. David, and John S. Earle, "Job Reallocation and Productivity Growth in the Ukrainian Transition," Comparative Economic Studies, Vol. 48, 229-251, June 2006.

Caballero, Ricardo J., and Mohammad L. Hammour, "On the Timing and Efficiency of Creative Destruction.” Quarterly Journal of Economics, Vol. 111(3), 805-851, 1996.

Davis, Steven J., and John C. Haltiwanger, "Gross Job Creation, Gross Job Destruction, and Employment Reallocation.” Quarterly Journal of Economics, Vol. 107(3), 819-863, August 1992.

Davis, Steven J., and John C. Haltiwanger. 1999. "Gross Job Flows," in Orley Ashenfelter and David Card, eds., Handbook of Labor Economics, Amsterdam: Elsevier, 2711-2805, 1999.

Disney, Richard, Jonathan Haskel, and Ylva Heden, "Restructuring and Productivity Growth in UK Manufacturing." mimeo, April 2000.

Disney, Richard, Jonathan Haskel, and Ylva Heden, "Restructuring and Productivity Growth in UK Manufacturing." Economic Journal, Vol. 113,666-694, July 2003.

Dunne, Timothy, Mark Roberts, and Larry Samuelson, "The Growth and Failure of U.S. Manufacturing Plants." Quarterly Journal of Economics, Vol. 104(4), 671-698, 1989.

Ericson, Richard, and Ariel Pakes, "Markov-Perfect Industry Dynamics: A Framework for Empirical Work." Review of Economic Studies, Vol. 62, 53-82, 1995.

Eslava, Marcela, John Haltiwanger, Adriana Kugler, and Maurice Kugler, "The Effects of Structural Reforms on Productivity and Profitability Enhancing Reallocation: Evidence from Colombia." Journal of Development Economics, Vol. 75(2), 333-371, 2004. 
Foster, Lucia, John C. Haltiwanger, and Cornell J. Krizan, "Aggregate Productivity Growth: Lessons from Microeconomic Evidence," in Edward Dean, Michael Harper, and Charles Hulten, eds., New Developments in Productivity Analysis, Chicago: University of Chicago Press, 303372, 2001.

Foster, Lucia, John Haltiwanger, and Chad Syverson, "Reallocation, Firm Turnover, and Efficiency: Selection on Productivity or Profitability?" American Economic Review, Vol. 98(1), 394-425, March 2008.

Frye, Timothy, and Andrei Shleifer, "The Invisible Hand and the Grabbing Hand." American Economic Review Papers and Proceedings, Vol. 87(2), 354-358, May 1997.

Granick, David, Job Rights in the Soviet Union. Cambridge, UK: Cambridge University Press, 1987.

Gregory, Paul, and Irwin L. Collier, Jr., "Unemployment in the Soviet Union: Evidence from the Soviet Interview Project." American Economic Review, Vol. 78(4), 613-632, September 1988.

Griliches, Zvi, and Haim Regev, "Firm Productivity in Israeli Industry 1979-1988." Journal of Econometrics, Vol. 65, 175-203, 1995.

Haltiwanger, John, "Measuring and Analyzing Aggregate Fluctuations: The Importance of Building from Microeconomic Evidence." Federal Reserve Bank of St. Louis Economic Review, 55-78, May/June 1997.

Hamermesh, Daniel, and Gerard Pfann, "Adjustment Costs in Factor Demand." Journal of Economic Literature, Vol. 34, 1264-92, September 1996.

Hopenhayn, Hugo, "Entry, Exit, and Firm Dynamics in Long Run Equilibrium." Econometrica, Vol. 60(5), 1127-1150, September 1992.

Hopenhayn, Hugo, and Richard Rogerson, "Job Turnover and Policy Evaluation: A General Equilibrium Analysis.” Journal of Political Economy, Vol. 101(5), 915-938, October 1993.

Jovanovic, Boyan, "Selection and the Evolution of Industry." Econometrica, Vol. 50(3), 649 670, May 1982.

Kornai, Janos, The Socialist System: The Political Economy of Communism. Princeton: Princeton University Press, 1992.

Liu, Lili, and James Tybout, "Productivity Growth in Chile and Columbia: The Role of Entry, Exit, and Learning." In Industrial Evolution in Developing countries: Micro Patterns of Turnover, Productivity, and Market Structure (Mark J. Robers and James R. Tybout, Editors). Oxford: Oxford University Press, 1996.

Olley, G. Steven, and Ariel Pakes, "The Dynamics of Productivity in the Telecommunications Equipment Industry.” Econometrica, Vol. 64(6), 1263-1297, November 1996.

Pavcnik, Nina, "Trade Liberalization, Exit, and Productivity Improvements: Evidence from Chilean Plants." Review of Economic Studies, Vol. 69, 245-276, 2002.

World Bank, From Plan to Market: World Development Report 1996. Oxford: Oxford University Press, 1996.

World Bank, Transition, The First Ten Years: Analysis and Lessons for Eastern Europe and the Former Soviet Union, World Bank, 2002. 
Figure 1: Annual Job Reallocation Rates

\section{1a: Job Creation}

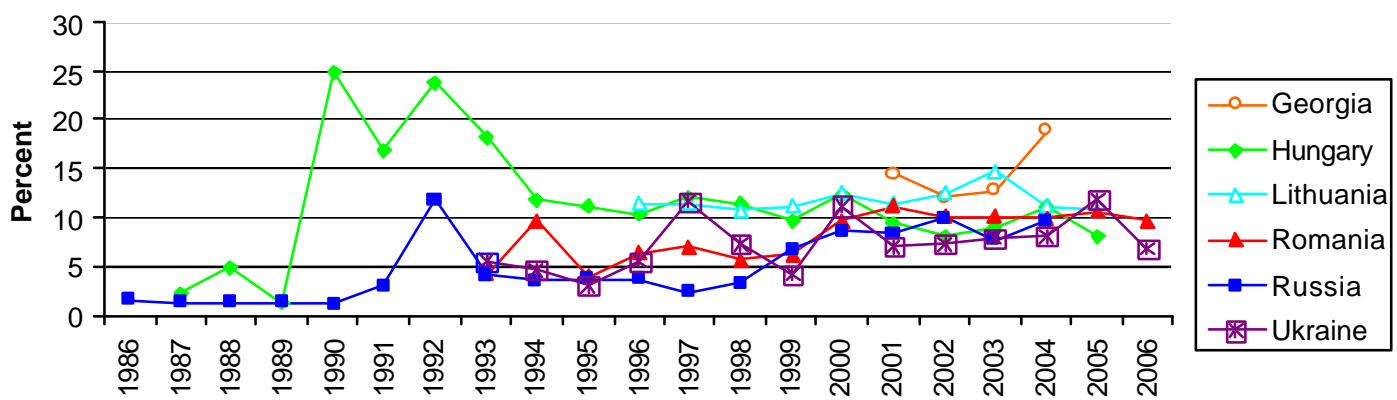

1b: Job Destruction

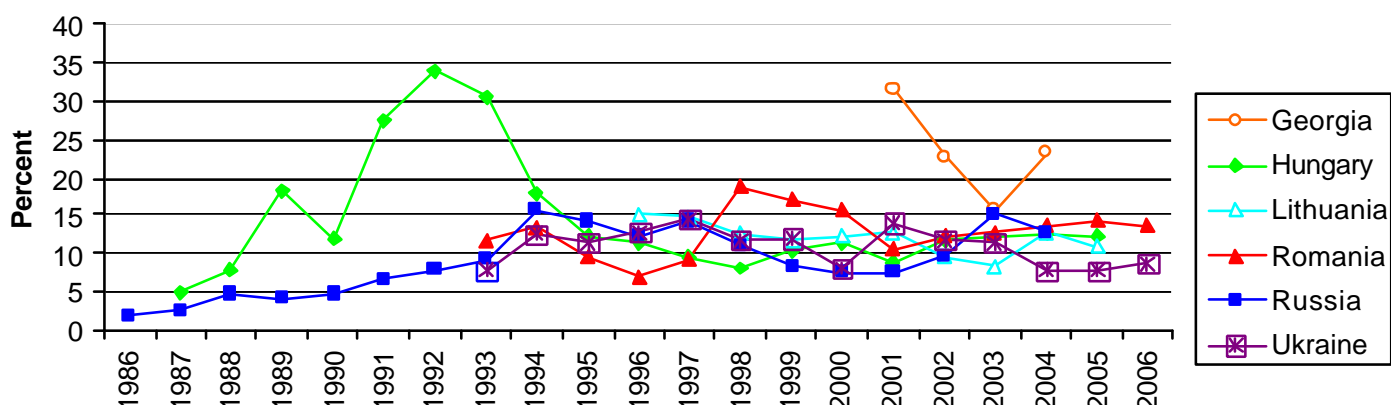

1c: Job Reallocation
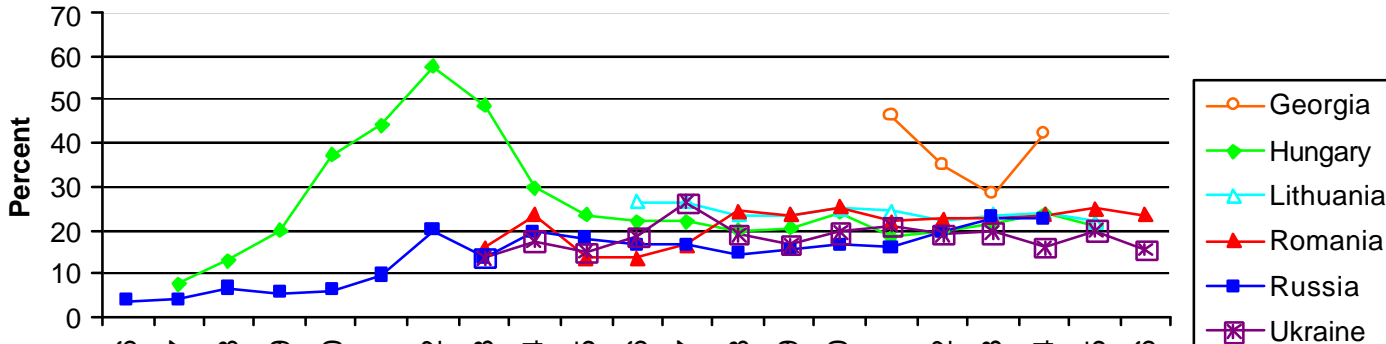

œ

1d: Intra-Industry Excess Job Reallocation

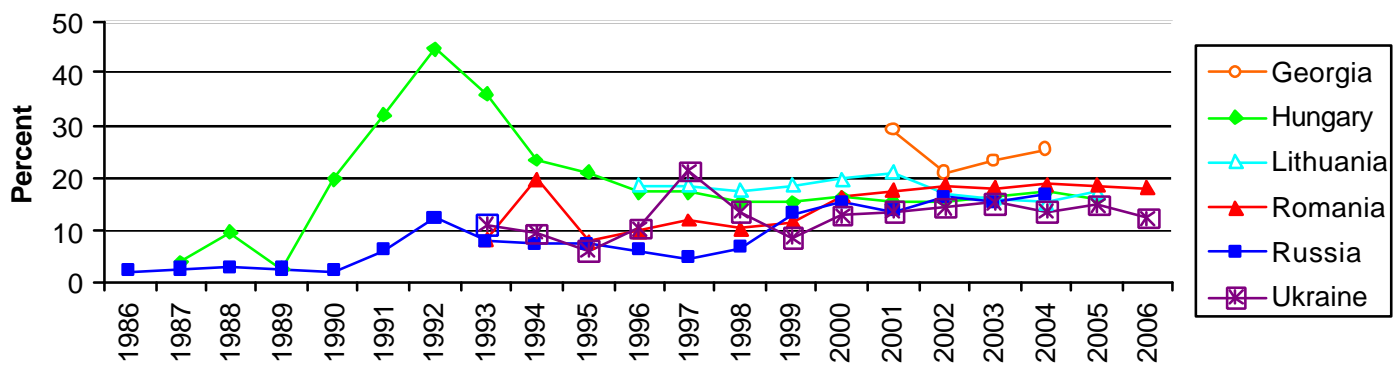


Figure 2: Three-Year Labor Productivity Decompositions

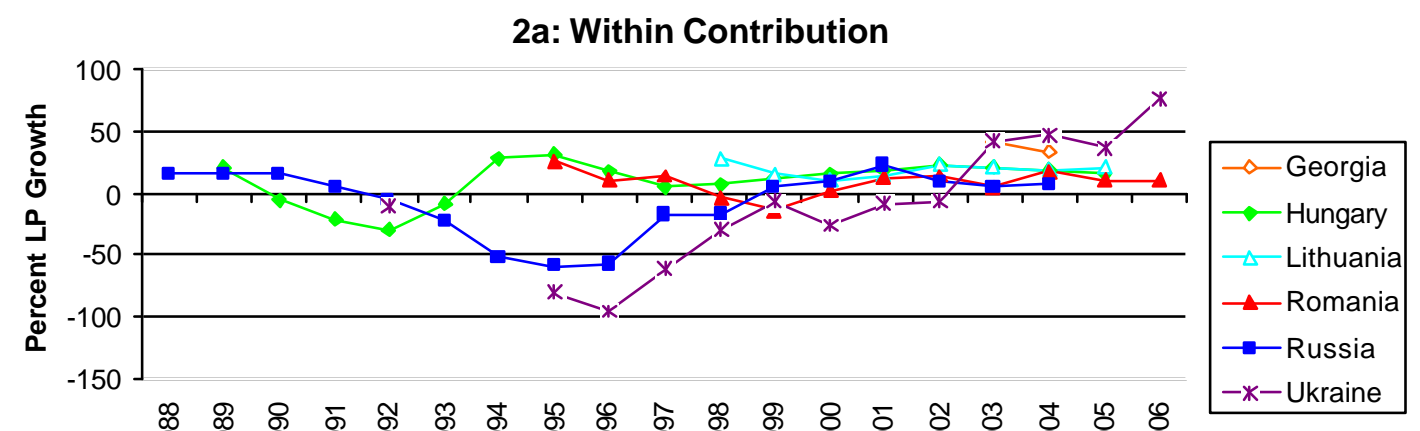

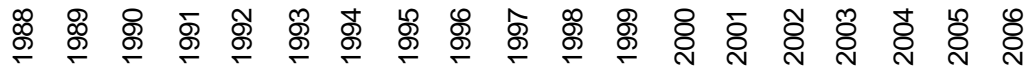

2b: Between Contribution

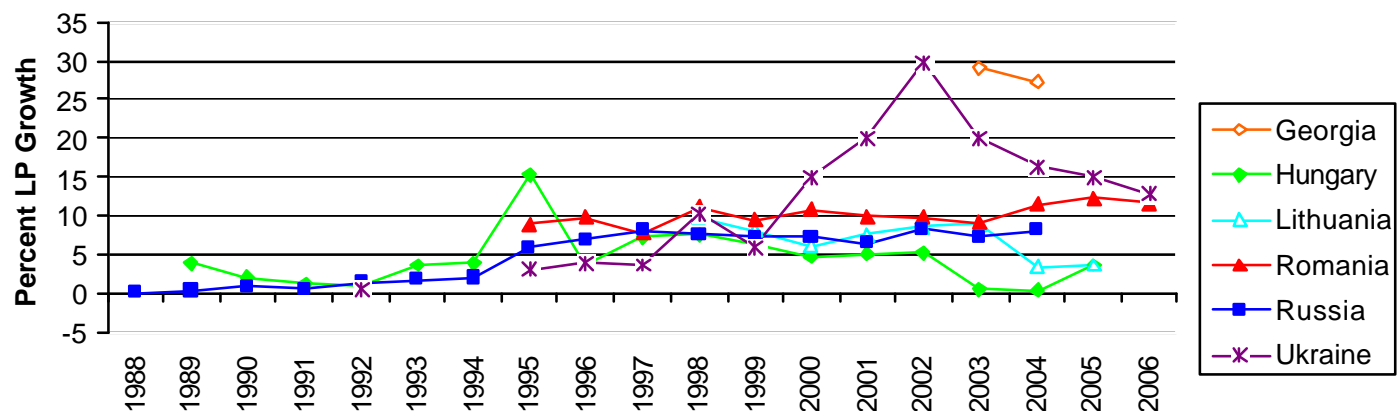

2c: Cross Contribution

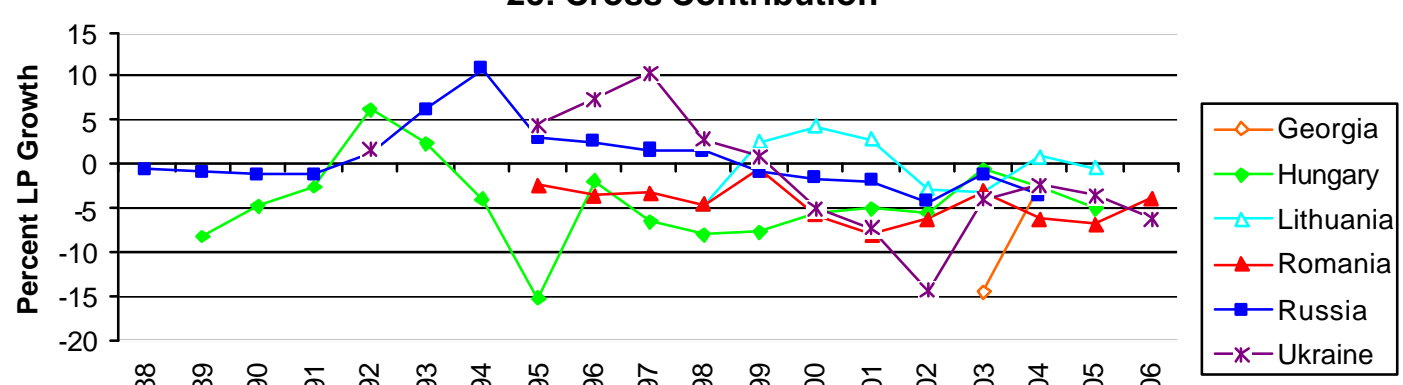

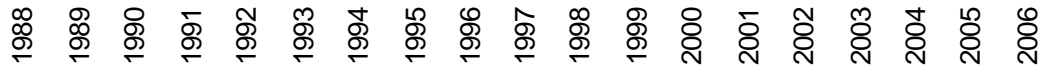




\section{2d: Proportionate Entry Contribution}

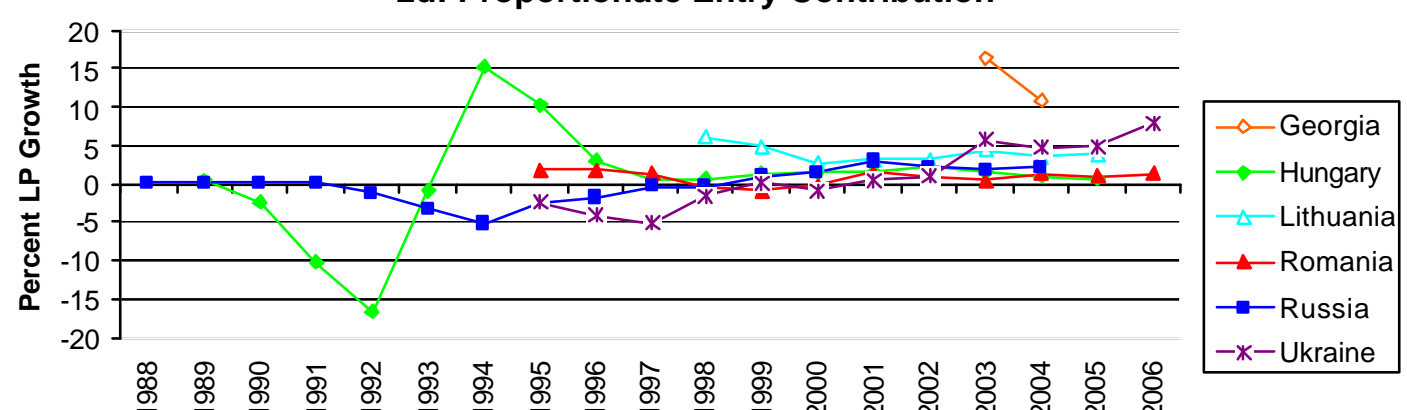

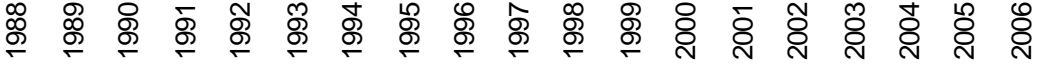

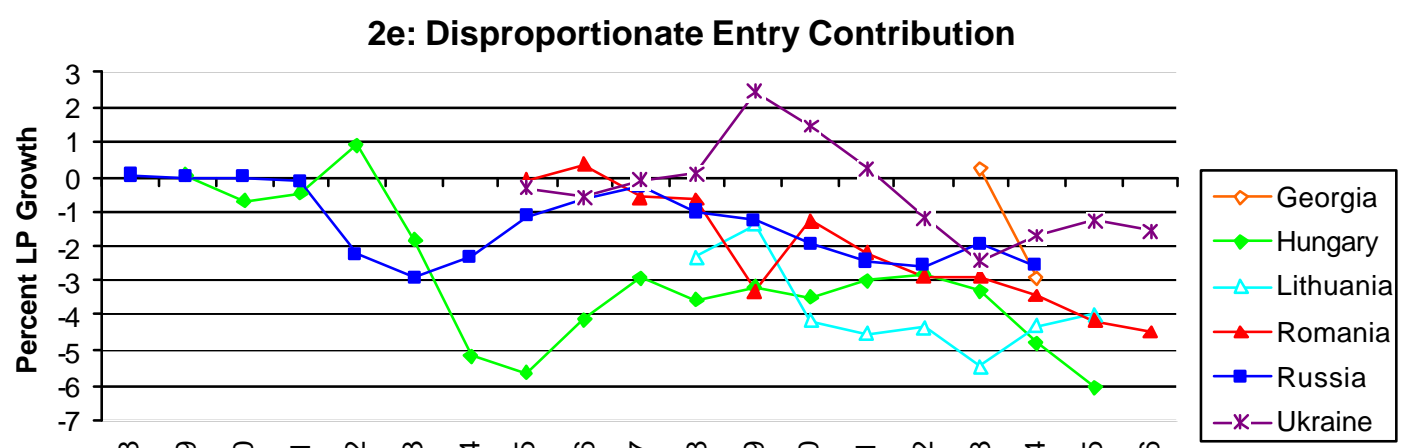

œ ஃ 유 ๙

\section{2f: Exit Contribution}

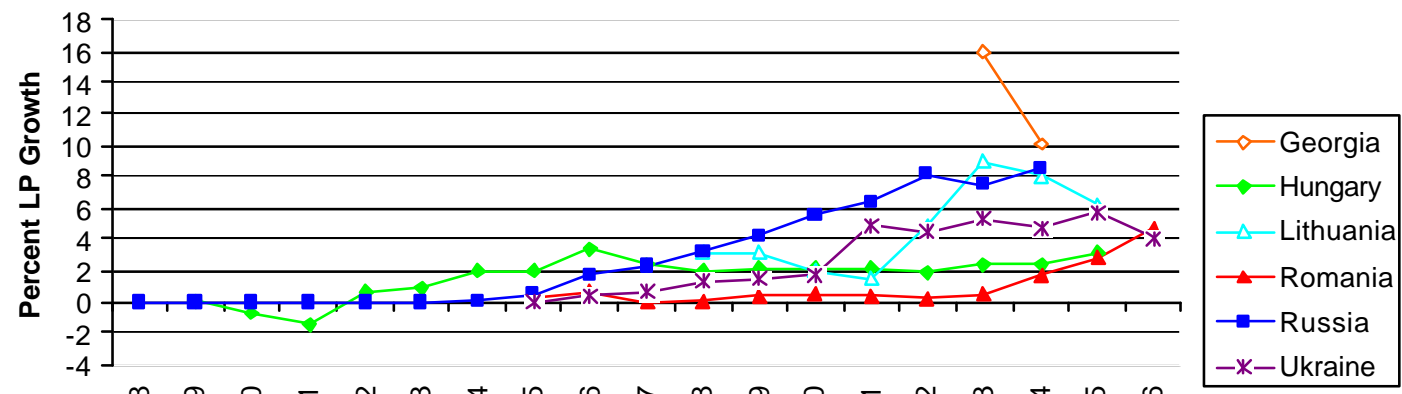

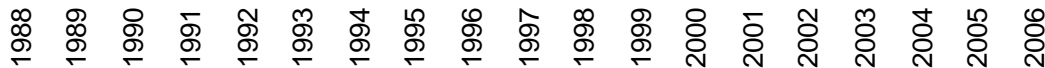




\section{2g: Total Reallocation Contribution}

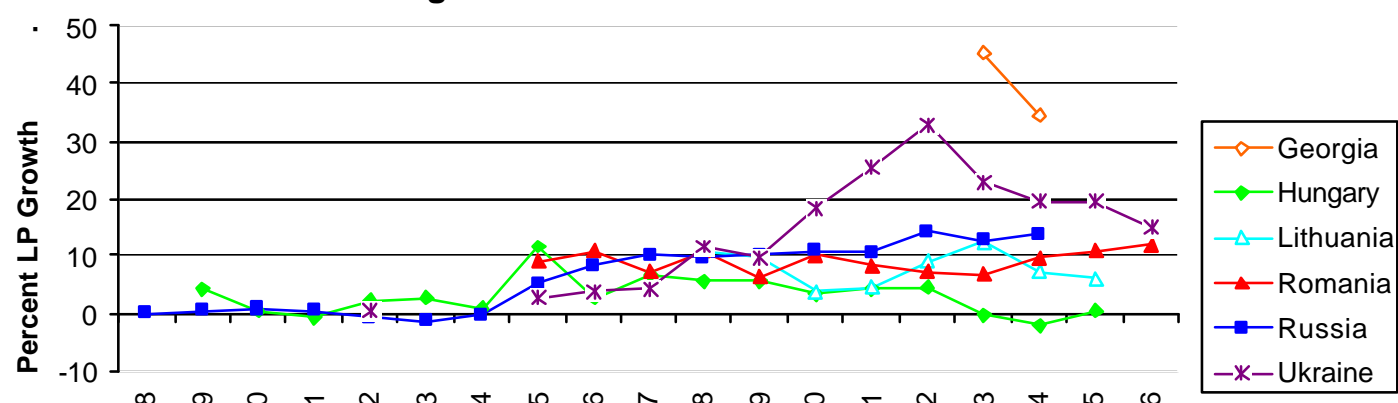

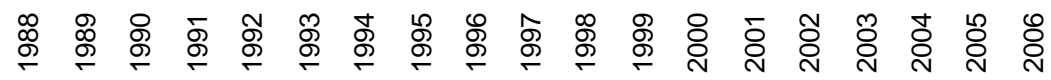

Note: The numbers behind these figures are in Appendix Table 1. Total reallocation contribution is defined as between contribution plus disproportionate entry contribution plus exit contribution. 
Figure 3: Disentangling the Entry Contribution

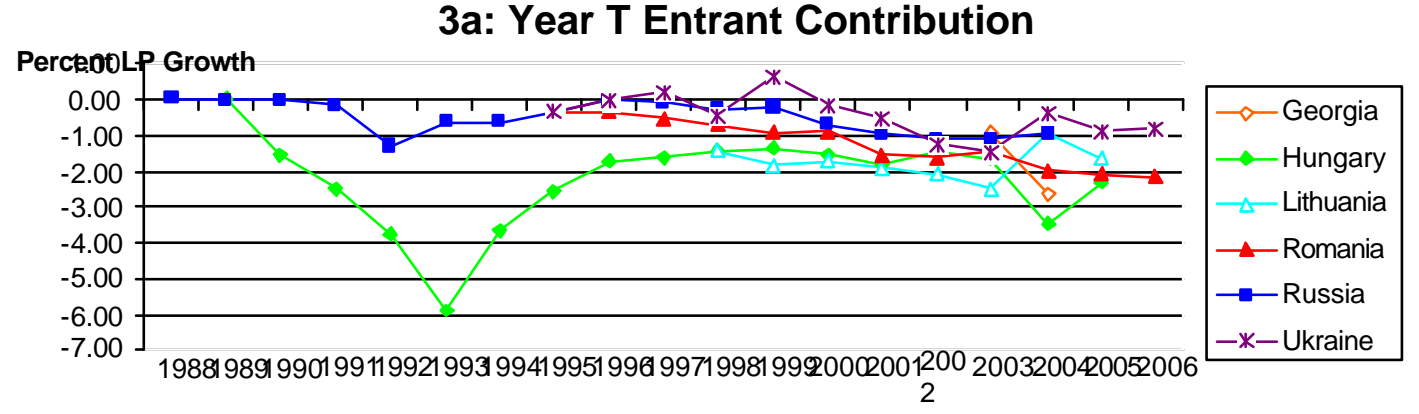

3b: Year T-1 Entrant Contribution

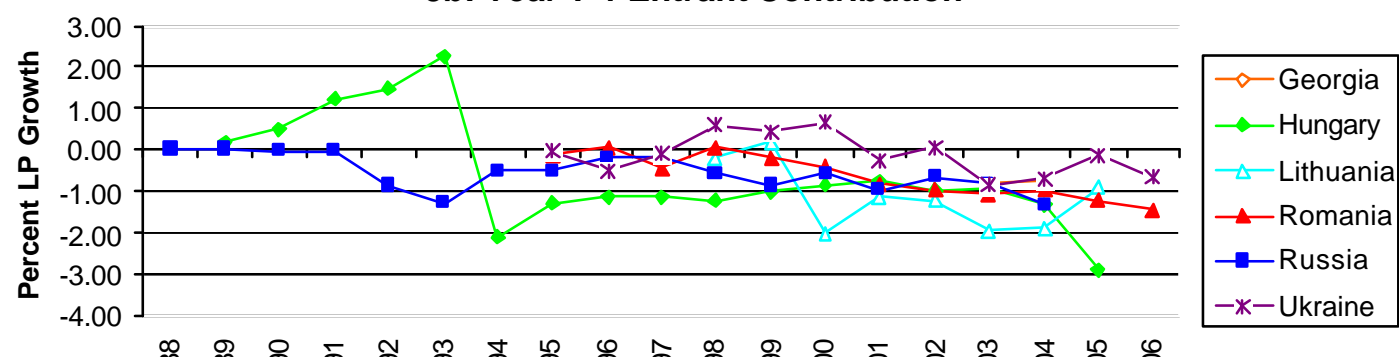

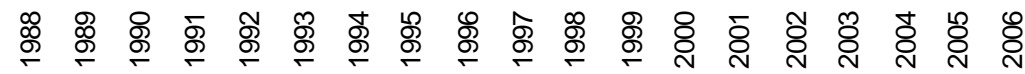

3c: Year T-2 Entrant Contribution

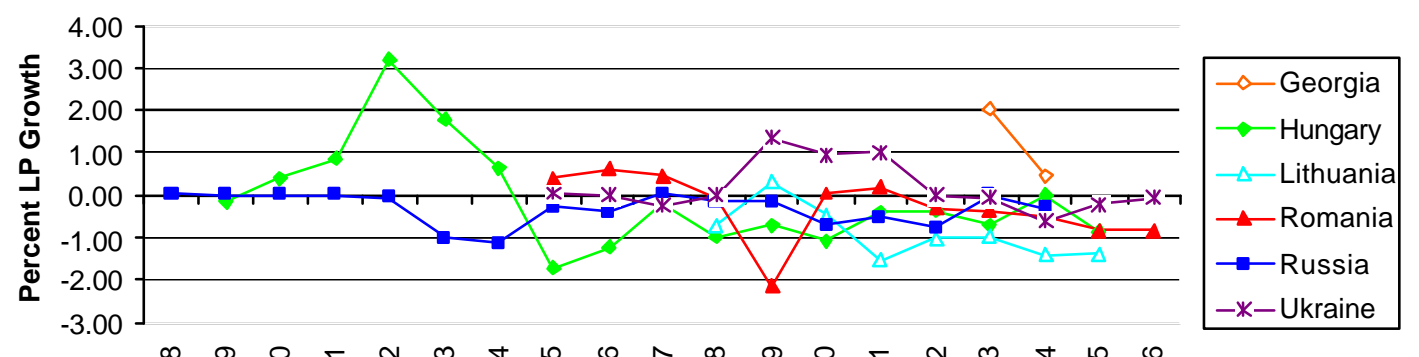

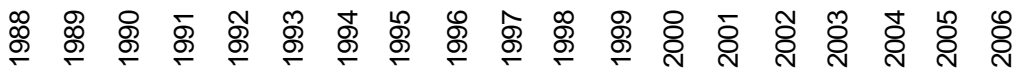

3d: T-2 Entrant Contributions Compared to Two Years Earlier

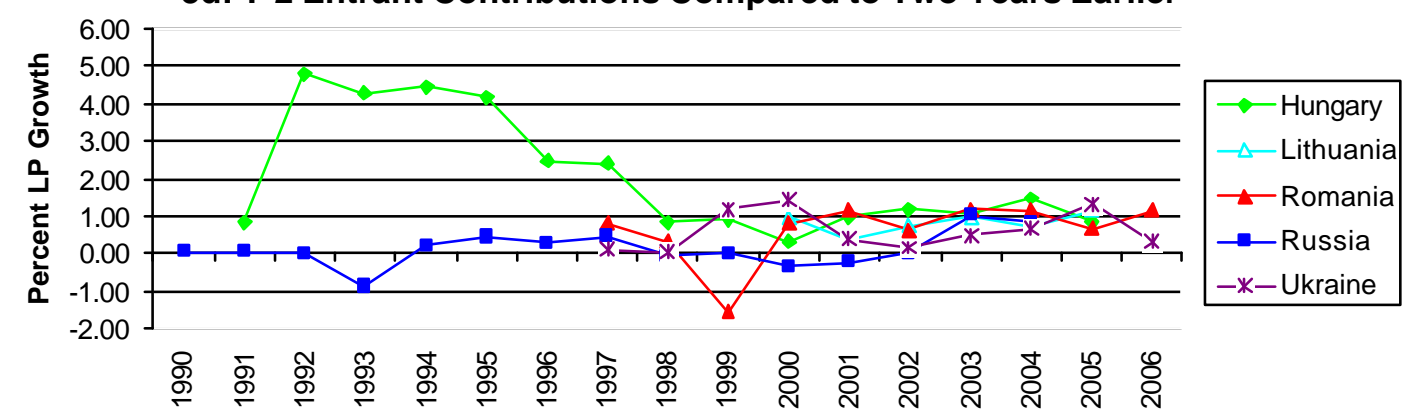

Note: These are disproportionate entry terms separately for each of the three entry cohorts in the three-year LP decompositions. Figure 11 takes the difference between the year T-2 contributions and what they were two years earlier as year $\mathrm{T}$ contributions. The numbers behind these figures are in Appendix Table 5. 
Figure 4: Learning and Selection Among Entrants Over Two Years

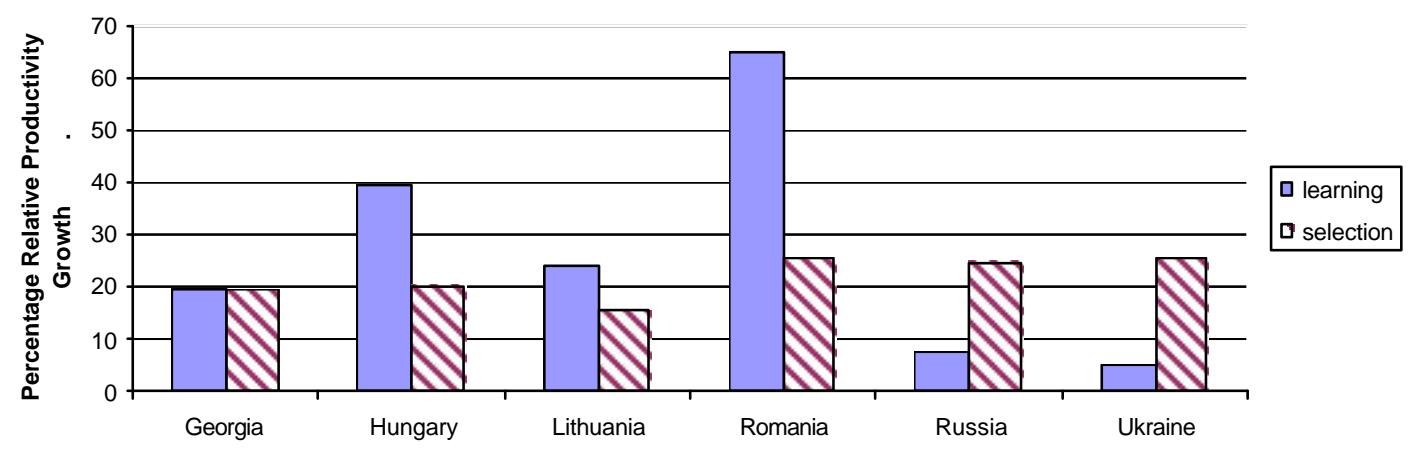

Note: Learning is the within term, and selection is the between and exit terms for a two-year labor productivity growth decomposition (minus entry terms) for fresh entrants, where firms' labor productivity is deviated from the contemporaneous industry level. These are average numbers over all two-year periods after the beginning of the transition (i.e., starting with 1991 entrants in Hungary, 1993 entrants in Romania, Russia, and Ukraine, and all available cohorts in Georgia and Lithuania). 
Figure 5: Reallocation and Labor Productivity Components
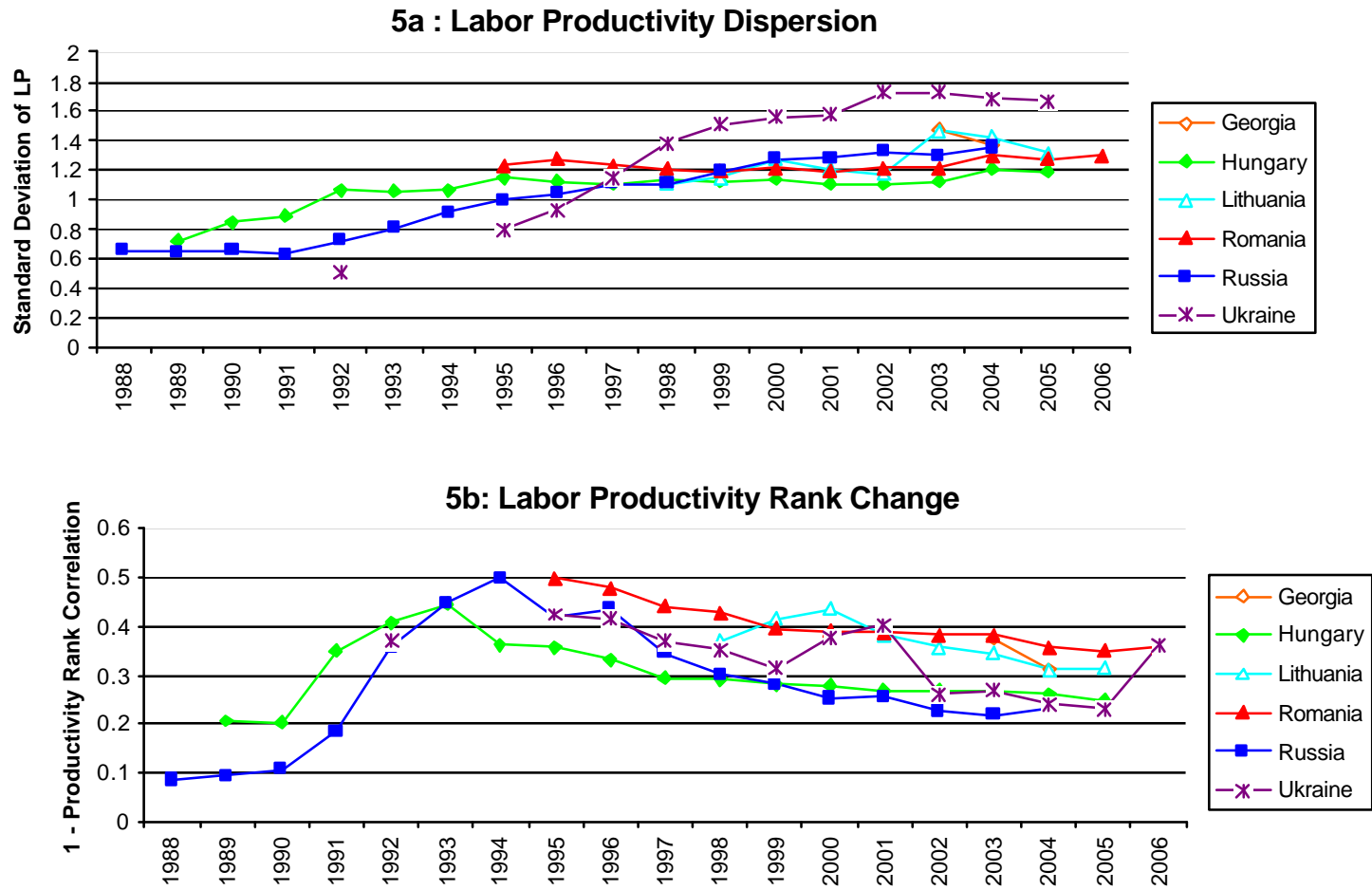

5c: Employment Share Change Dispersion

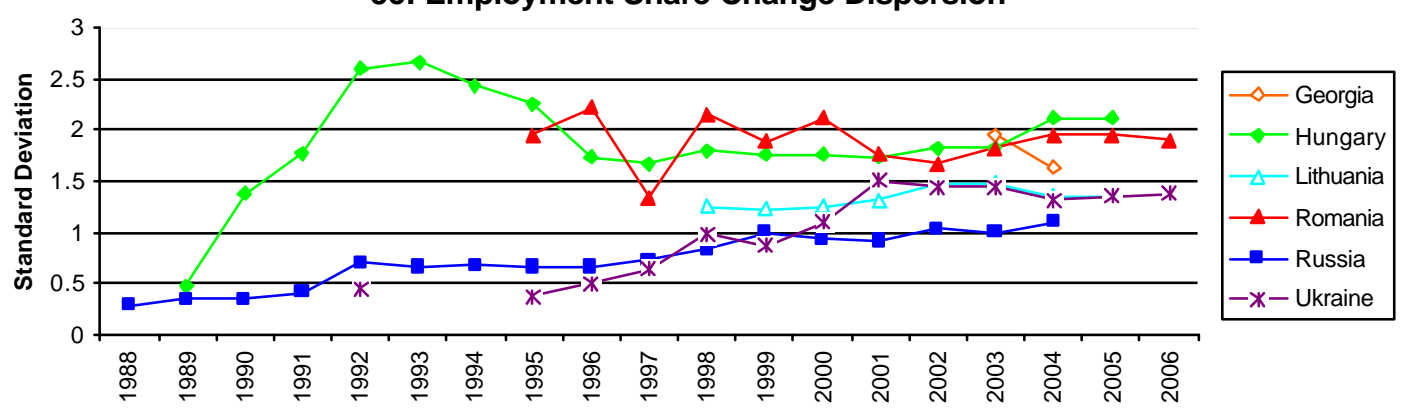

5d: Employment Share Change - Productivity Correlation

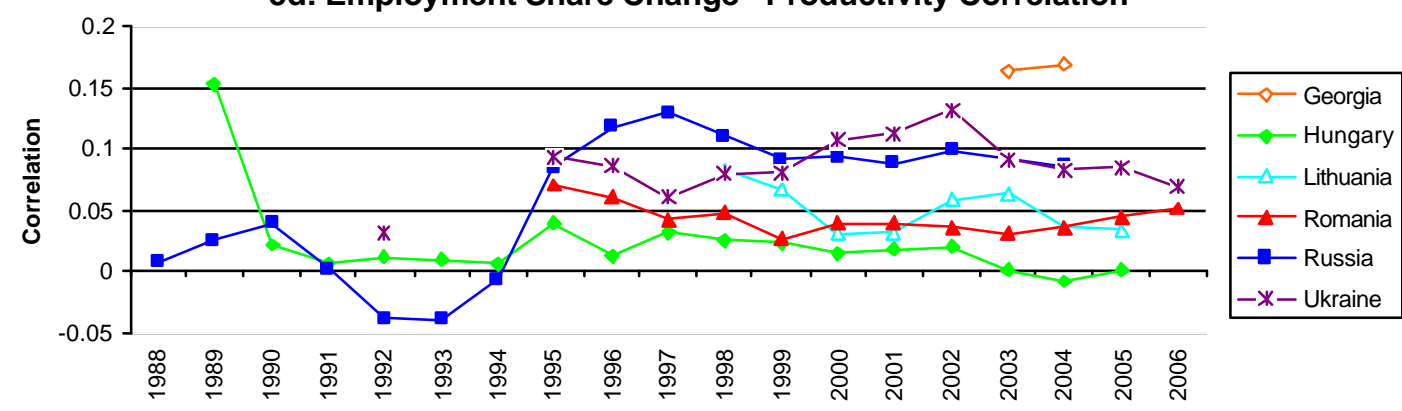


Note: These are three-year averages using the samples for the three-year labor productivity decompositions. The year on the $\mathrm{x}$ - axis refers to the final year in the decomposition. The numbers for these figures are shown in Appendix Table 6.

Table 1: Mean Output, Employment and Capital Stock in the First and Last Years of Analysis

\begin{tabular}{|c|c|c|c|c|c|c|}
\hline & \multicolumn{2}{|c|}{ Employment } & \multicolumn{2}{|c|}{ Output or Sales } & \multicolumn{2}{|c|}{ Capital Stock } \\
\hline & First year & Last year & First year & Last year & First year & Last year \\
\hline Georgia & $\begin{array}{c}30.9 \\
(122.9)\end{array}$ & $\begin{array}{c}23.9 \\
(87.6)\end{array}$ & $\begin{array}{l}302.5 \\
\quad(1,517.6)\end{array}$ & $\begin{array}{l}526.2 \\
\quad(3,291.5)\end{array}$ & $\begin{array}{c}442.0 \\
(3935.4)\end{array}$ & $\begin{array}{l}342.4 \\
\quad(2,033.3)\end{array}$ \\
\hline Hungary & $\begin{array}{l}700.1 \\
(1,181.0)\end{array}$ & $\begin{array}{l}23.7 \\
(138.7)\end{array}$ & $\begin{array}{r}7,054.2 \\
(22,492.0)\end{array}$ & $\begin{array}{l}594.5 \\
\quad(14,377.8)\end{array}$ & $\begin{array}{r}2,364.1 \\
(9,372.5)\end{array}$ & $\begin{array}{l}190.0 \\
\quad(3,514.5)\end{array}$ \\
\hline Lithuania & $\begin{array}{c}131.1 \\
(404.8)\end{array}$ & $\begin{array}{c}45.1 \\
(148.7)\end{array}$ & $\begin{array}{r}6,465.5 \\
(30,697.9)\end{array}$ & $\begin{array}{r}7,296.8 \\
(158,200.7)\end{array}$ & $\begin{array}{r}3,362.0 \\
(16,159.0)\end{array}$ & $\begin{array}{r}2,712.6 \\
(28,307.3)\end{array}$ \\
\hline Romania & $\begin{array}{c}257.3 \\
(1062.4)\end{array}$ & $\begin{array}{c}35.3 \\
(182.5)\end{array}$ & $\begin{array}{r}105,167.7 \\
(682,720.1)\end{array}$ & $\begin{array}{r}38,879.0 \\
(605,725.2)\end{array}$ & $\begin{array}{r}835,676.5 \\
(3,365,040.2)\end{array}$ & $\begin{array}{r}22,640.7 \\
(327,126.2)\end{array}$ \\
\hline Russia & $\begin{array}{l}819.9 \\
(2,637.7)\end{array}$ & $\begin{array}{l}366.9 \\
(1,461.9)\end{array}$ & $\begin{array}{c}520.4 \\
(1499.8)\end{array}$ & $\begin{array}{l}525.5 \\
\quad(5,674.7)\end{array}$ & $\begin{array}{l}355.3 \\
\quad(1,439.6)\end{array}$ & $\begin{array}{l}827.6 \\
\quad(18,959.7)\end{array}$ \\
\hline Ukraine & $\begin{array}{l}783.2 \\
(1,865.9)\end{array}$ & $\begin{array}{c}85.8 \\
(764.1)\end{array}$ & $\begin{array}{c}53.9 \\
(170.5)\end{array}$ & $\begin{array}{c}13.2 \\
(201.4)\end{array}$ & $\begin{array}{c}37.2 \\
(168.6)\end{array}$ & $\begin{array}{c}17.2 \\
(418.9)\end{array}$ \\
\hline
\end{tabular}

Note: The first year of analysis is 1985 in Russia, 1986 in Hungary, 1989 in Ukraine, 1992 in Romania, 1995 in Lithuania, and 2000 in Georgia; the last year is 2004 in Georgia and Russia, 2005 for Hungary and Lithuania, and 2006 for Romania and Ukraine. Employment is the average annual number of all registered employees, except in Russia, where it excludes personnel working in non-industrial divisions. Output or sales refers to sales in Georgia, Hungary, Lithuania, Romania, and post 2003 Ukraine, and to value of production in Russia and pre-2004 Ukraine. Capital stock is the book value of fixed assets. Output or sales and capital stock are expressed in constant final-year prices (thousands of 2004 GEL for Georgia, millions of 2005 HUF for Hungary, thousands of 2005 LTL for Lithuania, millions of 2006 ROL for Romania, millions of 2004 RUB for Russia, and millions 2006 UAH for Ukraine). Standard deviations are shown in parentheses. 
Table 2: Long-Run Productivity Growth Decompositions

\begin{tabular}{|c|c|c|c|c|c|c|c|}
\hline & Total & Within & Between & Cross & $\begin{array}{l}\text { Prop. } \\
\text { Entry }\end{array}$ & $\begin{array}{c}\text { Disprop. } \\
\text { Entry }\end{array}$ & Exit \\
\hline \multicolumn{8}{|l|}{ United Kingdom } \\
\hline 1980-1992 LP & 70.17 & 33.68 & 2.81 & -0.70 & 29.47 & \multicolumn{2}{|c|}{$4.91 *$} \\
\hline 1980-1992 MFP & 13.49 & 0.67 & 2.02 & 3.51 & 5.67 & \multicolumn{2}{|c|}{$1.61 *$} \\
\hline \multicolumn{8}{|l|}{ United States } \\
\hline 1977-1987 LP & 23.02 & 17.03 & 1.84 & -2.53 & 4.83 & \multicolumn{2}{|c|}{$1.84^{*}$} \\
\hline 1977-1987 MFP & 10.24 & 4.92 & -0.82 & 3.48 & 2.15 & \multicolumn{2}{|c|}{$0.51 *$} \\
\hline \multicolumn{8}{|l|}{ Hungary } \\
\hline 1990-2005 LP & 53.31 & 29.31 & -1.67 & -14.67 & 43.13 & -4.55 & 1.76 \\
\hline 1990-2005 MFP & 37.94 & 8.34 & -1.85 & 0.41 & 30.97 & -0.41 & 0.48 \\
\hline \multicolumn{8}{|l|}{ Lithuania } \\
\hline 1995-2005 LP & 109.63 & 50.81 & 4.41 & -1.99 & 50.45 & -6.43 & 12.39 \\
\hline 1995-2005 MFP & 107.48 & 44.35 & 8.45 & -7.21 & 50.35 & 2.55 & 9.01 \\
\hline \multicolumn{8}{|l|}{ Romania } \\
\hline 1992-2006 LP & 86.09 & 51.10 & 7.22 & -13.63 & 41.85 & -3.33 & 2.88 \\
\hline 1992-2006 MFP & 89.75 & 46.88 & 4.26 & -8.67 & 46.12 & -1.50 & 2.66 \\
\hline \multicolumn{8}{|l|}{ Russia } \\
\hline 1992-2004 LP & -1.98 & -11.69 & 7.12 & 1.22 & -2.58 & -1.85 & 5.80 \\
\hline 1992-2004 MFP & 9.26 & -2.81 & 6.23 & -2.18 & 1.88 & 2.24 & 3.90 \\
\hline \multicolumn{8}{|l|}{ Ukraine } \\
\hline 1992-2006 LP & 67.46 & 17.64 & 7.74 & 11.21 & 24.65 & 3.24 & 2.98 \\
\hline 1992-2006 MFP & 54.21 & -0.21 & 7.39 & 16.69 & 22.98 & 4.34 & 3.02 \\
\hline
\end{tabular}

Note: These calculations are based on Equation (4) in the text. The Exit term is $-\sum_{e \in X} s_{e t-1}\left(p_{e t-1}-P_{i t-1}\right)$, so a positive value means a positive contribution to productivity growth. The U.K. results are based on Disney et al. (2003), and the U.S. numbers on Haltiwanger (1997) and Foster et al. (2001). These papers apply a similar equation (except that the Entry and Exit components are combined, and Proportionate Entry is not distinguished) to establishment data, using base-year worker-hours (U.K. LP and MFP and U.S. LP) or output (U.S. MFP) as weights; the labor measure is worker-hours. The Proportionate Entry numbers for the U.S. and U.K. are our calculations based on figures available in the text of these papers. 
Table 3a: Decomposition of Cross-Country Reallocation Contribution Differences in 1992-1995

\begin{tabular}{llllll}
\hline & $\begin{array}{c}\text { Productivity } \\
\text { Dispersion } \\
\text { Component }\end{array}$ & $\begin{array}{c}\text { Employment } \\
\text { Share Change } \\
\text { Component }\end{array}$ & $\begin{array}{c}\text { Correlation } \\
\text { Component }\end{array}$ & $\begin{array}{c}\text { Industry } \\
\text { Share } \\
\text { Component }\end{array}$ & $\begin{array}{c}\text { Total } \\
\text { Reallocation } \\
\text { Contribution } \\
\text { Difference }\end{array}$ \\
\hline Romania-Hungary & 1.18 & -7.61 & 4.78 & -0.93 & -2.58 \\
Russia-Hungary & -1.39 & -9.32 & 4.46 & -0.17 & -6.43 \\
Ukraine-Hungary & -3.22 & -11.84 & 6.92 & -0.85 & -9.00 \\
Russia-Romania & -1.48 & -6.92 & 4.91 & -0.36 & -3.84 \\
Ukraine-Romania & -5.03 & -15.02 & 14.68 & -1.05 & -6.42 \\
Ukraine-Russia & -1.13 & -2.75 & 1.51 & -0.21 & -2.58 \\
\hline
\end{tabular}

Note: These are decompositions of the differences in the total reallocation contribution to three-year labor productivity growth in the two countries in 1992-1995, applying equation (5). The numbers are percentage points of productivity growth. 
Table 3b: Decomposition of Cross-Country Reallocation Contribution Differences in Latest Period

\begin{tabular}{|c|c|c|c|c|c|}
\hline & $\begin{array}{l}\text { Productivity } \\
\text { Dispersion } \\
\text { Component }\end{array}$ & $\begin{array}{l}\text { Employment } \\
\text { Share Change } \\
\text { Component }\end{array}$ & $\begin{array}{l}\text { Correlation } \\
\text { Component }\end{array}$ & $\begin{array}{c}\text { Industry } \\
\text { Share } \\
\text { Component }\end{array}$ & $\begin{array}{c}\text { Total } \\
\text { Reallocation } \\
\text { Contribution } \\
\text { Difference } \\
\end{array}$ \\
\hline Georgia-Hungary 2001-2004 & 2.92 & -12.46 & 42.31 & 3.90 & 36.66 \\
\hline Lithuania-Hungary 2002-2005 & 0.40 & -3.12 & 7.38 & 0.66 & 5.33 \\
\hline Romania-Hungary 2002-2005 & 0.69 & -0.96 & 13.07 & -2.35 & 10.45 \\
\hline Russia-Hungary 2001-2004 & 2.10 & -9.65 & 27.59 & -3.86 & 16.17 \\
\hline Ukraine-Hungary 2002-2005 & 5.09 & -6.18 & 25.42 & -5.42 & 18.91 \\
\hline Georgia-Lithuania 2001-2004 & 1.63 & 3.61 & 23.08 & -0.95 & 27.36 \\
\hline Romania-Lithuania 2002-2005 & -0.25 & 3.81 & 1.43 & 0.13 & 5.12 \\
\hline Russia-Lithuania 2002-2005 & -0.25 & -2.02 & 15.70 & -6.56 & 6.87 \\
\hline Ukraine-Lithuania 2002-2005 & 3.44 & 2.33 & 14.24 & -6.43 & 13.58 \\
\hline Georgia-Romania 2001-2004 & 3.26 & -5.87 & 19.27 & 8.10 & 24.76 \\
\hline Russia-Romania 2001 -2004 & 0.54 & -6.69 & 13.98 & -3.56 & 4.27 \\
\hline Ukraine-Romania 2003-2006 & 3.55 & -4.14 & 8.76 & -4.96 & 3.21 \\
\hline Georgia-Russia 2001-2004 & 2.99 & 5.03 & 7.59 & 4.89 & 20.50 \\
\hline Ukraine-Russia 2001-2004 & 3.26 & 3.67 & -0.64 & -0.74 & 5.55 \\
\hline Georgia-Ukraine 2001-2004 & -7.02 & 5.25 & 20.97 & -4.26 & 14.94 \\
\hline
\end{tabular}

Note: These are decompositions of the differences in the total reallocation contribution to three-year labor productivity growth in the two countries over the stated time period, applying equation (5). The numbers are percentage points of productivity growth. 
Table 4: Incumbent Firm Cleansing Potential and Volume Regressions

\begin{tabular}{lllll}
\hline & $\begin{array}{c}\text { Employment } \\
\text { Share } \\
\text { Change } \\
\text { Dispersion }\end{array}$ & $\begin{array}{c}\text { Employment } \\
\text { Share } \\
\text { Change- } \\
\text { Productivity } \\
\text { Correlation }\end{array}$ & $\begin{array}{c}\text { Incumbent } \\
\text { Productivity } \\
\text { Dispersion } \\
\text { Change }\end{array}$ & $\begin{array}{c}\text { Incumbent } \\
\text { Productivity } \\
\text { Dispersion } \\
\text { Change }\end{array}$ \\
\hline $\begin{array}{l}\text { Incumbents' Initial } \\
\text { Productivity Dispersion }\end{array}$ & $\begin{array}{l}0.830^{* * *} \\
\text { Incumbent Employment Share }\end{array}$ & $0.063^{* * *}$ & & \\
$\begin{array}{l}\text { Change-Productivity } \\
\text { Correlation }\end{array}$ & $(0.018)$ & & $-0.147^{*}$ \\
Incumbent Employment Share & & & -0.142 & $(0.088)$ \\
Change Dispersion & & & $-0.089)$ & $-0.067^{* * * * *}$ \\
Incumbent Employment Share & & & $(0.009)$ & $(0.019)$ \\
Change Dispersion Squared & & 0.251 & 0.369 & $0.007 * *$ \\
$\mathrm{R}^{2}$ & 0.408 & 0.372
\end{tabular}

Note: $\mathrm{N}=1,330$. The units of observation are country-industry -year cells, pooling data from Georgia, Hungary, Lithuania, Romania, Russia, and Ukraine. Each regression also contains industry, country, and year effects. Standard errors adjusted for clustering on country-industries are in parentheses. $*=$ significant at the 10 percent level, $* *=$ significant at the 5 percent level, and $* * *=$ significant at the 1 percent level. Employment change dispersion, employment changeproductivity correlation, and productivity dispersion change are over three-year periods. Change in productivity dispersion is defined as $\frac{\left(\sigma_{p_{e t}-P_{i t}}-\sigma_{p_{e t-3}-P_{i t-3}}\right) \times 2}{\left(\sigma_{p_{e t}-P_{i t}}+\sigma_{p_{e t-3}-P_{i t-3}}\right)}$. The dependent variables in the first two columns include entrant activity. 
Appendix Figure 1: Total Reallocation Contribution (Employment $>100$ )

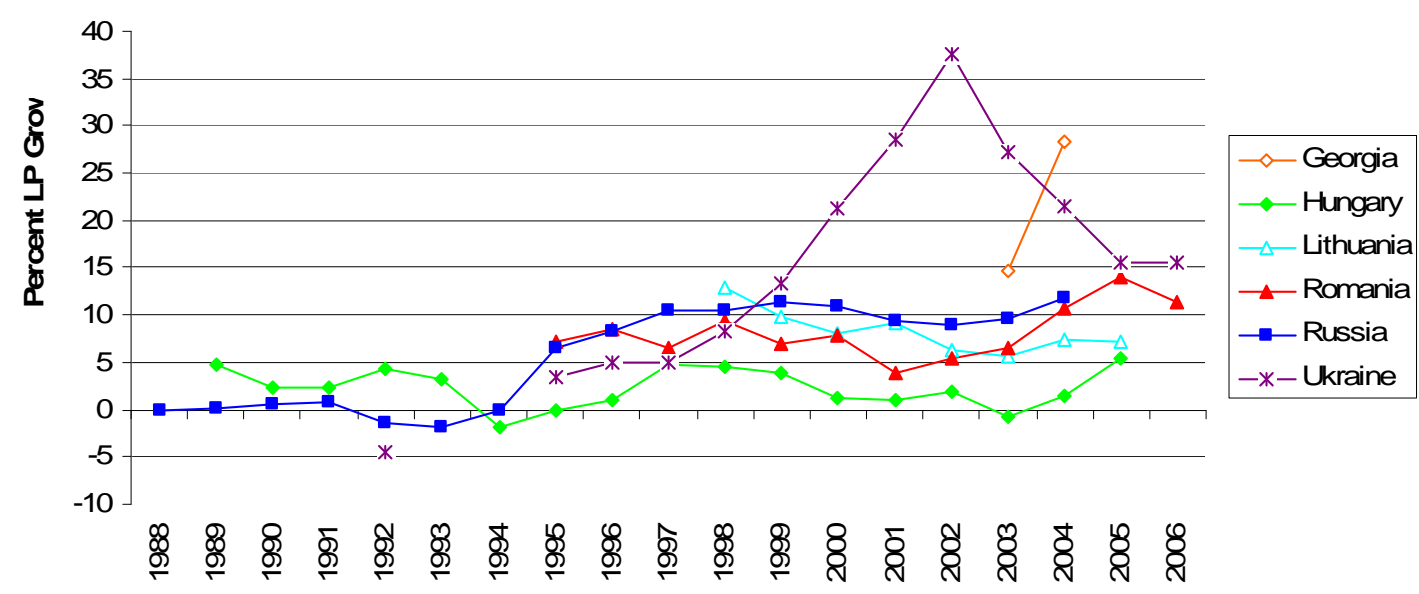

Note: Total reallocation is defined as between + disproportionate entry + exit. This decomposition is done with samples where employment of 100 or below is set to missing, entry is defined as the first year a firm has more than 100 employees, and exit is defined as the year after the last year the firm has more than 100 employees. 


\section{Appendix Table 1a: Job Flows in Georgian Manufacturing}

\begin{tabular}{llcccccc}
\hline & Job Creation & $\begin{array}{c}\text { Job } \\
\text { Destruction }\end{array}$ & $\begin{array}{c}\text { Job } \\
\text { Reallocation }\end{array}$ & $\begin{array}{c}\text { Excess Job } \\
\text { Realloc. }\end{array}$ & $\begin{array}{c}\text { Within- } \\
\text { Sector } \\
\text { Excess } \\
\text { Job } \\
\text { Realloc. }\end{array}$ & $\begin{array}{c}\text { Entry } \\
\text { Share of } \\
\text { Emp. }\end{array}$ & $\begin{array}{c}\text { Exit Share } \\
\text { of Emp. }\end{array}$ \\
\hline $2000-01$ & 14.63 & 31.71 & 46.34 & 29.26 & 29.02 & 7.82 & 9.28 \\
$2001-02$ & 12.17 & 22.76 & 34.93 & 24.34 & 20.93 & 5.39 & 6.69 \\
$2002-03$ & 12.73 & 15.73 & 28.46 & 25.46 & 23.36 & 3.87 & 6.66 \\
$2003-04$ & 18.93 & 23.35 & 42.28 & 37.86 & 25.57 & 8.09 & 10.74 \\
\hline
\end{tabular}

Note: The job flow measures use methods from Davis and Haltiwanger (1992).

\section{Appendix Table 1b: Job Flows in Hungarian Manufacturing}

\begin{tabular}{lccccccc}
\hline & Job & Job & Job & Excess Job \\
Creation & Destruction & $\begin{array}{c}\text { Within- } \\
\text { Rector } \\
\text { Recess Job } \\
\text { Realloc. }\end{array}$ & $\begin{array}{c}\text { Entry } \\
\text { Share of } \\
\text { Emp. }\end{array}$ & $\begin{array}{c}\text { Exit Share } \\
\text { of Emp. }\end{array}$ \\
\hline $1986-87$ & 2.27 & 5.02 & 7.29 & 4.54 & 3.82 & 0.71 & 0.16 \\
$1987-88$ & 4.92 & 7.94 & 12.86 & 9.84 & 9.61 & 1.90 & 0.48 \\
$1988-89$ & 1.31 & 18.31 & 19.62 & 2.62 & 2.61 & 0.52 & 0.33 \\
$1989-90$ & 25.02 & 12.06 & 37.08 & 24.12 & 19.69 & 8.98 & 1.14 \\
$1990-91$ & 16.99 & 27.27 & 44.26 & 33.98 & 31.78 & 8.76 & 4.72 \\
$1991-92$ & 23.82 & 33.96 & 57.78 & 47.64 & 44.69 & 17.11 & 11.74 \\
$1992-93$ & 18.29 & 30.42 & 48.71 & 36.58 & 35.87 & 11.68 & 12.53 \\
$1993-94$ & 11.87 & 18.01 & 29.88 & 23.73 & 23.16 & 5.13 & 6.27 \\
$1994-95$ & 11.26 & 12.24 & 23.49 & 22.51 & 20.76 & 2.86 & 4.04 \\
$1995-96$ & 10.35 & 11.43 & 21.78 & 20.69 & 17.20 & 2.67 & 3.03 \\
$1996-97$ & 12.22 & 9.63 & 21.85 & 19.26 & 17.38 & 3.03 & 2.88 \\
$1997-98$ & 11.56 & 8.05 & 19.61 & 16.10 & 15.12 & 2.11 & 2.10 \\
$1998-99$ & 9.72 & 10.49 & 20.21 & 19.44 & 15.34 & 2.00 & 2.33 \\
$1999-00$ & 12.31 & 11.34 & 23.65 & 22.68 & 16.51 & 2.33 & 3.45 \\
$2000-01$ & 9.49 & 9.07 & 18.56 & 18.14 & 15.73 & 2.01 & 2.23 \\
$2001-02$ & 8.07 & 11.77 & 19.84 & 16.15 & 15.39 & 2.13 & 2.46 \\
$2002-03$ & 9.15 & 12.34 & 21.49 & 18.30 & 16.53 & 1.69 & 3.51 \\
$2003-04$ & 11.15 & 12.48 & 23.63 & 22.29 & 17.20 & 4.11 & 3.07 \\
$2004-05$ & 8.23 & 12.43 & 20.66 & 16.47 & 15.98 & 1.69 & 4.49 \\
\hline
\end{tabular}




\section{Appendix Table 1c: Job Flows in Lithuanian Manufacturing}

\begin{tabular}{llcccccc}
\hline & $\begin{array}{c}\text { Job } \\
\text { Creation }\end{array}$ & $\begin{array}{c}\text { Job } \\
\text { Destruction }\end{array}$ & $\begin{array}{c}\text { Job } \\
\text { Reallocation }\end{array}$ & $\begin{array}{c}\text { Excess Job } \\
\text { Realloc. }\end{array}$ & $\begin{array}{c}\text { Within- } \\
\text { Sector } \\
\text { Excess Job } \\
\text { Realloc. }\end{array}$ & $\begin{array}{c}\text { Entry } \\
\text { Share of } \\
\text { Emp. }\end{array}$ & $\begin{array}{c}\text { Exit Share } \\
\text { of Emp. }\end{array}$ \\
\hline $1995-96$ & 11.48 & 15.01 & 26.49 & 22.96 & 18.26 & 7.52 & 1.19 \\
$1996-97$ & 11.55 & 14.79 & 26.34 & 23.10 & 18.59 & 5.35 & 1.99 \\
$1997-98$ & 10.79 & 12.69 & 23.48 & 21.58 & 17.42 & 5.14 & 1.95 \\
$1998-99$ & 11.31 & 11.86 & 23.17 & 22.61 & 18.41 & 6.79 & 0.63 \\
$1999-00$ & 12.55 & 12.41 & 24.95 & 24.82 & 19.50 & 3.09 & 0.38 \\
$2000-01$ & 11.57 & 12.92 & 24.49 & 23.14 & 20.72 & 2.69 & 2.20 \\
$2001-02$ & 12.55 & 9.42 & 21.97 & 18.85 & 16.86 & 3.08 & 2.31 \\
$2002-03$ & 14.73 & 8.39 & 23.12 & 16.78 & 16.17 & 4.02 & 1.68 \\
$2003-04$ & 11.20 & 12.79 & 23.99 & 22.40 & 15.32 & 2.24 & 1.53 \\
$2004-05$ & 10.78 & 10.82 & 21.60 & 21.56 & 17.05 & 3.53 & 2.37 \\
\hline
\end{tabular}

\section{Appendix Table 1d: Job Flows in Romanian Manufacturing}

\begin{tabular}{lccccccc}
\hline & $\begin{array}{c}\text { Job } \\
\text { Creation }\end{array}$ & $\begin{array}{c}\text { Job } \\
\text { Destruction }\end{array}$ & $\begin{array}{c}\text { Job } \\
\text { Reallocation }\end{array}$ & $\begin{array}{c}\text { Excess Job } \\
\text { Realloc. }\end{array}$ & $\begin{array}{c}\text { Within- } \\
\text { Sector } \\
\text { Excess Job } \\
\text { Realloc. }\end{array}$ & $\begin{array}{c}\text { Entry } \\
\text { Share of } \\
\text { Emp. }\end{array}$ & $\begin{array}{c}\text { Exit Share } \\
\text { of Emp. }\end{array}$ \\
\hline $1992-93$ & 4.27 & 11.74 & 16.01 & 8.54 & 8.33 & 2.13 & 0.19 \\
$1993-94$ & 9.75 & 13.55 & 23.30 & 19.49 & 19.49 & 1.45 & 0.15 \\
$1994-95$ & 3.89 & 9.59 & 13.48 & 7.79 & 7.73 & 1.03 & 0.13 \\
$1995-96$ & 6.38 & 6.88 & 13.25 & 12.75 & 9.91 & 0.70 & 0.25 \\
$1996-97$ & 6.95 & 9.25 & 16.21 & 13.91 & 11.82 & 1.04 & 0.15 \\
$1997-98$ & 5.80 & 18.66 & 24.46 & 11.60 & 10.13 & 1.19 & 0.31 \\
$1998-99$ & 6.22 & 17.07 & 23.30 & 12.45 & 11.49 & 1.41 & 0.45 \\
$1999-00$ & 9.65 & 15.55 & 25.20 & 19.29 & 16.39 & 1.48 & 0.48 \\
$2000-01$ & 11.35 & 10.56 & 21.91 & 21.12 & 17.62 & 1.90 & 0.67 \\
$2001-02$ & 10.11 & 12.44 & 22.55 & 20.21 & 18.30 & 1.99 & 0.54 \\
$2002-03$ & 10.06 & 12.79 & 22.86 & 20.12 & 17.93 & 2.13 & 0.70 \\
$2003-04$ & 9.90 & 13.67 & 23.57 & 19.80 & 18.70 & 2.04 & 0.79 \\
$2004-05$ & 10.60 & 14.23 & 24.84 & 21.21 & 18.36 & 1.99 & 1.89 \\
$2005-06$ & 9.76 & 13.61 & 23.37 & 19.53 & 18.14 & 1.92 & 2.30 \\
\hline
\end{tabular}




\section{Appendix Table 1e: Job Flows in Russian Manufacturing}

\begin{tabular}{lccccccc}
\hline & Job & Job & Job & Excess Job \\
Creation & Destruction & $\begin{array}{c}\text { Within- } \\
\text { Sector } \\
\text { Recess Job } \\
\text { Realloc. }\end{array}$ & $\begin{array}{c}\text { Entry } \\
\text { Share of } \\
\text { Emp. }\end{array}$ & $\begin{array}{c}\text { Exit Share } \\
\text { of Emp. }\end{array}$ \\
\hline $1985-86$ & 1.57 & 1.85 & 3.43 & 3.15 & 2.22 & 0.00 & 0.00 \\
$1986-87$ & 1.36 & 2.52 & 3.88 & 2.73 & 2.66 & 0.00 & 0.00 \\
$1987-88$ & 1.40 & 4.82 & 6.22 & 2.79 & 2.79 & 0.01 & 0.00 \\
$1988-89$ & 1.31 & 4.23 & 5.55 & 2.63 & 2.60 & 0.02 & 0.00 \\
$1989-90$ & 1.11 & 4.83 & 5.95 & 2.23 & 2.23 & 0.15 & 0.00 \\
$1990-91$ & 3.06 & 6.62 & 9.68 & 6.12 & 6.12 & 0.88 & 0.00 \\
$1991-92$ & 11.83 & 7.86 & 19.69 & 15.72 & 12.41 & 3.98 & 0.00 \\
$1992-93$ & 4.10 & 9.32 & 13.43 & 8.21 & 7.83 & 1.27 & 0.02 \\
$1993-94$ & 3.63 & 15.66 & 19.28 & 7.25 & 7.25 & 1.25 & 0.53 \\
$1994-95$ & 3.71 & 14.30 & 18.02 & 7.43 & 7.43 & 0.97 & 0.90 \\
$1995-96$ & 3.82 & 12.39 & 16.21 & 7.65 & 6.25 & 0.26 & 1.63 \\
$1996-97$ & 2.33 & 14.16 & 16.50 & 4.66 & 4.66 & 0.32 & 0.79 \\
$1997-98$ & 3.29 & 11.18 & 14.47 & 6.58 & 6.58 & 0.50 & 1.51 \\
$1998-99$ & 6.79 & 8.41 & 15.21 & 13.59 & 12.98 & 0.82 & 1.06 \\
$1999-00$ & 8.67 & 7.59 & 16.27 & 15.19 & 14.97 & 1.44 & 1.31 \\
$2000-01$ & 8.46 & 7.46 & 15.92 & 14.92 & 13.57 & 1.94 & 1.49 \\
$2001-02$ & 9.90 & 9.70 & 19.60 & 19.39 & 16.59 & 3.09 & 1.57 \\
$2002-03$ & 7.63 & 15.02 & 22.65 & 15.27 & 15.05 & 3.07 & 1.48 \\
$2003-04$ & 9.62 & 12.77 & 22.39 & 19.24 & 16.94 & 2.67 & 1.48 \\
\hline
\end{tabular}

\section{Appendix Table 1f: Job Flows in Ukrainian Manufacturing}

\begin{tabular}{lccccccc}
\hline & $\begin{array}{c}\text { Job } \\
\text { Creation }\end{array}$ & $\begin{array}{c}\text { Job } \\
\text { Destruction }\end{array}$ & $\begin{array}{c}\text { Job } \\
\text { Reallocation }\end{array}$ & $\begin{array}{c}\text { Excess Job } \\
\text { Realloc. }\end{array}$ & $\begin{array}{c}\text { Within- } \\
\text { Sector } \\
\text { Excess Job } \\
\text { Realloc. }\end{array}$ & $\begin{array}{c}\text { Entry } \\
\text { Share of } \\
\text { Emp. }\end{array}$ & $\begin{array}{c}\text { Exit Share } \\
\text { of Emp. }\end{array}$ \\
\hline $1992-93$ & 5.62 & 7.83 & 13.45 & 11.24 & 11.24 & 1.40 & \\
$1993-94$ & 4.64 & 12.60 & 17.24 & 9.28 & 9.28 & 1.35 & 0.49 \\
$1994-95$ & 3.16 & 11.61 & 14.76 & 6.32 & 6.32 & 0.91 & 0.49 \\
$1995-96$ & 5.53 & 12.77 & 18.30 & 11.06 & 10.43 & 1.95 & 0.68 \\
$1996-97$ & 11.68 & 14.62 & 26.30 & 23.35 & 21.29 & 6.16 & 0.81 \\
$1997-98$ & 7.26 & 11.61 & 18.87 & 14.52 & 13.60 & 3.32 & 0.86 \\
$1998-99$ & 4.29 & 11.93 & 16.23 & 8.59 & 8.59 & 0.78 & 1.22 \\
$1999-00$ & 11.36 & 8.18 & 19.54 & 16.36 & 12.78 & 0.95 & 0.18 \\
$2000-01$ & 7.00 & 13.87 & 20.87 & 14.00 & 13.43 & 1.72 & 1.68 \\
$2001-02$ & 7.19 & 11.78 & 18.97 & 14.38 & 14.34 & 1.76 & 0.29 \\
$2002-03$ & 7.83 & 11.59 & 19.42 & 15.67 & 15.28 & 1.97 & 1.22 \\
$2003-04$ & 8.12 & 7.89 & 16.01 & 15.78 & 13.69 & 0.70 & 0.39 \\
$2004-05$ & 11.96 & 7.77 & 19.73 & 15.53 & 14.55 & 4.46 & 0.97 \\
$2005-06$ & 6.85 & 8.73 & 15.58 & 13.70 & 12.37 & 1.26 & 0.13 \\
\hline
\end{tabular}


Appendix Table 2: Three-Year Labor Productivity Growth Decompositions

\begin{tabular}{|c|c|c|c|c|c|c|c|}
\hline & Total & Within & Between & Cross & $\begin{array}{l}\text { Prop. } \\
\text { Entry }\end{array}$ & $\begin{array}{c}\text { Disprop. } \\
\text { Entry }\end{array}$ & Exit \\
\hline \multicolumn{8}{|l|}{ Georgia } \\
\hline $2000-2003$ & 87.95 & 40.75 & 29.15 & -14.56 & 16.43 & 0.25 & 15.92 \\
\hline 2001-2004 & 74.16 & 31.43 & 27.30 & -2.44 & 10.65 & -2.93 & 10.14 \\
\hline \multicolumn{8}{|l|}{ Hungary } \\
\hline 1986-1989 & 16.80 & 20.45 & 3.94 & -8.21 & 0.48 & 0.05 & 0.09 \\
\hline 1987-1990 & -12.04 & -5.43 & 1.95 & -4.80 & -2.33 & -0.71 & -0.72 \\
\hline 1988-1991 & -34.61 & -21.15 & 1.22 & -2.57 & -10.20 & -0.44 & -1.47 \\
\hline 1989-1992 & -39.00 & -30.86 & 0.81 & 6.09 & -16.53 & 0.88 & 0.62 \\
\hline $1990-1993$ & -4.65 & -8.76 & 3.73 & 2.38 & -1.08 & -1.82 & 0.89 \\
\hline 1991-1994 & 39.37 & 27.50 & 3.94 & -4.19 & 15.33 & -5.16 & 1.95 \\
\hline 1992-1995 & 36.52 & 29.99 & 15.41 & -15.46 & 10.25 & -5.61 & 1.95 \\
\hline 1993-1996 & 19.80 & 15.93 & 3.54 & -1.88 & 2.92 & -4.10 & 3.39 \\
\hline 1994-1997 & 5.49 & 4.64 & 7.21 & -6.48 & 0.57 & -2.93 & 2.48 \\
\hline 1995-1998 & 5.14 & 6.61 & 7.38 & -7.90 & 0.61 & -3.56 & 2.00 \\
\hline 1996-1999 & 9.71 & 10.61 & 6.51 & -7.74 & 1.29 & -3.15 & 2.18 \\
\hline $1997-2000$ & 14.79 & 15.33 & 4.78 & -5.63 & 1.58 & -3.48 & 2.22 \\
\hline 1998-2001 & 18.27 & 17.71 & 4.93 & -5.08 & 1.61 & -3.00 & 2.11 \\
\hline 1999-2002 & 23.28 & 22.28 & 5.39 & -5.54 & 2.12 & -2.81 & 1.83 \\
\hline $2000-2003$ & 19.75 & 19.31 & 0.62 & -0.78 & 1.44 & -3.30 & 2.45 \\
\hline 2001-2004 & 14.02 & 17.72 & 0.25 & -2.61 & 1.06 & -4.80 & 2.40 \\
\hline 2002-2005 & 10.66 & 14.43 & 3.56 & -5.03 & 0.73 & -6.09 & 3.06 \\
\hline \multicolumn{8}{|l|}{ Lithuania } \\
\hline 1995-1998 & 38.95 & 27.03 & 9.85 & -4.68 & 5.89 & -2.31 & 3.17 \\
\hline 1996-1999 & 31.94 & 14.85 & 7.95 & 2.62 & 4.85 & -1.38 & 3.05 \\
\hline $1997-2000$ & 20.45 & 9.83 & 6.04 & 4.17 & 2.59 & -4.16 & 1.98 \\
\hline $1998-2001$ & 22.86 & 12.41 & 7.51 & 2.77 & 3.30 & -4.56 & 1.43 \\
\hline 1999-2002 & 30.94 & 21.49 & 8.58 & -2.86 & 3.26 & -4.36 & 4.84 \\
\hline $2000-2003$ & 32.93 & 19.28 & 8.94 & -3.13 & 4.27 & -5.46 & 9.04 \\
\hline 2001-2004 & 30.24 & 18.55 & 3.33 & 0.93 & 3.62 & -4.27 & 8.09 \\
\hline 2002-2005 & 30.16 & 20.97 & 3.52 & -0.53 & 3.87 & -3.98 & 6.31 \\
\hline \multicolumn{8}{|l|}{ Romania } \\
\hline 1992-1995 & 33.57 & 25.00 & 9.01 & -2.36 & 1.76 & -0.07 & 0.23 \\
\hline 1993-1996 & 18.38 & 9.22 & 9.73 & -3.50 & 1.94 & 0.37 & 0.60 \\
\hline 1994-1997 & 17.35 & 12.54 & 7.67 & -3.44 & 1.13 & -0.56 & 0.01 \\
\hline 1995-1998 & 0.94 & -4.71 & 11.21 & -4.65 & -0.43 & -0.65 & 0.17 \\
\hline 1996-1999 & -10.29 & -14.94 & 9.37 & -0.74 & -1.02 & -3.32 & 0.37 \\
\hline $1997-2000$ & 5.94 & 1.83 & 10.79 & -5.89 & -0.07 & -1.26 & 0.54 \\
\hline 1998-2001 & 13.01 & 11.31 & 10.06 & -8.02 & 1.42 & -2.19 & 0.42 \\
\hline 1999-2002 & 14.84 & 12.87 & 9.83 & -6.32 & 1.11 & -2.89 & 0.23 \\
\hline $2000-2003$ & 7.89 & 3.82 & 9.25 & -3.21 & 0.33 & -2.87 & 0.57 \\
\hline 2001-2004 & 22.03 & 17.20 & 11.40 & -6.20 & 1.27 & -3.44 & 1.79 \\
\hline 2002-2005 & 15.17 & 10.23 & 12.29 & -6.89 & 0.87 & -4.15 & 2.83 \\
\hline 2003-2006 & 19.57 & 10.09 & 11.64 & -3.80 & 1.36 & -4.44 & 4.72 \\
\hline
\end{tabular}




\begin{tabular}{clllllll}
\hline & Total & Within & Between & Cross & $\begin{array}{c}\text { Prop. } \\
\text { Entry }\end{array}$ & $\begin{array}{c}\text { Disprop. } \\
\text { Entry }\end{array}$ & Exit \\
\hline Russia & & & & & & & \\
$1985-1988$ & 14.97 & 15.62 & -0.02 & -0.68 & 0.01 & 0.04 & 0.00 \\
$1986-1989$ & 13.59 & 14.30 & 0.30 & -1.01 & 0.00 & -0.01 & 0.00 \\
$1987-1990$ & 14.57 & 14.96 & 0.74 & -1.11 & 0.02 & -0.05 & 0.00 \\
$1988-1991$ & 3.42 & 4.08 & 0.45 & -1.03 & 0.07 & -0.14 & 0.00 \\
$1989-1992$ & -6.34 & -5.68 & 1.49 & 1.28 & -1.19 & -2.24 & 0.00 \\
$1990-1993$ & -22.18 & -24.00 & 1.69 & 6.20 & -3.13 & -2.95 & 0.00 \\
$1991-1994$ & -47.23 & -52.78 & 2.03 & 10.95 & -5.22 & -2.29 & 0.07 \\
$1992-1995$ & -53.72 & -59.42 & 5.96 & 3.05 & -2.67 & -1.12 & 0.49 \\
$1993-1996$ & -48.90 & -57.63 & 6.98 & 2.49 & -1.88 & -0.64 & 1.78 \\
$1994-1997$ & -5.99 & -17.35 & 8.14 & 1.55 & -0.36 & -0.25 & 2.28 \\
$1995-1998$ & -7.37 & -18.02 & 7.41 & 1.42 & -0.38 & -1.00 & 3.20 \\
$1996-1999$ & 14.83 & 4.68 & 7.20 & -0.82 & 0.86 & -1.23 & 4.15 \\
$1997-2000$ & 19.34 & 8.72 & 7.31 & -1.77 & 1.41 & -1.95 & 5.61 \\
$1998-2001$ & 33.81 & 22.33 & 6.43 & -1.84 & 2.92 & -2.45 & 6.41 \\
$1999-2002$ & 20.28 & 8.28 & 8.41 & -4.28 & 2.23 & -2.53 & 8.17 \\
$2000-2003$ & 18.05 & 4.48 & 7.24 & -1.12 & 1.93 & -1.94 & 7.47 \\
$2001-2004$ & 19.07 & 6.66 & 8.05 & -3.71 & 2.10 & -2.58 & 8.55 \\
\hline Ukraine & & & & & & & \\
$1989-1992$ & -9.46 & -11.63 & 0.57 & 1.60 & n.a. & n.a. & n.a. \\
$1992-1995$ & -74.94 & -79.83 & 3.06 & 4.38 & -2.24 & -0.33 & 0.02 \\
$1993-1996$ & -88.33 & -95.34 & 4.03 & 7.35 & -4.12 & -0.57 & 0.33 \\
$1994-1997$ & -52.10 & -61.62 & 3.73 & 10.46 & -5.24 & -0.11 & 0.68 \\
$1995-1998$ & -17.13 & -30.13 & 10.35 & 2.76 & -1.54 & 0.11 & 1.32 \\
$1996-1999$ & 2.41 & -8.30 & 5.91 & 0.85 & 0.01 & 2.42 & 1.51 \\
$1997-2000$ & -14.78 & -26.82 & 14.91 & -5.15 & -0.99 & 1.47 & 1.81 \\
$1998-2001$ & 9.66 & -8.68 & 20.11 & -7.38 & 0.47 & 0.21 & 4.93 \\
$1999-2002$ & 11.81 & -7.65 & 29.63 & -14.41 & 1.00 & -1.19 & 4.43 \\
$2000-2003$ & 64.44 & 40.26 & 19.93 & -4.17 & 5.61 & -2.42 & 5.23 \\
$2001-2004$ & 67.99 & 46.34 & 16.47 & -2.48 & 4.55 & -1.68 & 4.78 \\
$2002-2005$ & 55.50 & 34.97 & 14.91 & -3.70 & 4.81 & -1.23 & 5.75 \\
$2003-2006$ & 91.90 & 75.17 & 12.65 & -6.39 & 7.99 & -1.57 & 4.05 \\
\hline
\end{tabular}

Note: These are labor productivity growth decompositions weighted by base-year employment. Labor productivity is the $\log$ of the ratio of real gross output divided by number of employees. They apply Equation (4) in the text. The exit term here is $-\sum_{e \in X} s_{e t-1}\left(p_{e t-1}-P_{i t-1}\right)$, so a positive exit term value means a positive contribution to productivity growth. 
Appendix Table 3: Three-Year Multifactor Productivity Growth Decompositions

\begin{tabular}{|c|c|c|c|c|c|c|c|}
\hline & Total & Within & Between & Cross & $\begin{array}{l}\text { Prop. } \\
\text { Entry }\end{array}$ & $\begin{array}{l}\text { Disprop. } \\
\text { Entry }\end{array}$ & Exit \\
\hline \multicolumn{8}{|l|}{ Georgia } \\
\hline $2000-2003$ & 69.04 & 26.80 & 19.62 & -8.09 & 13.49 & 1.40 & 15.81 \\
\hline 2001-2004 & 67.30 & 27.38 & 24.18 & -0.56 & 9.36 & -0.41 & 7.36 \\
\hline \multicolumn{8}{|l|}{ Hungary } \\
\hline 1986-1989 & 12.35 & 13.77 & 2.38 & -4.12 & 0.29 & 0.16 & -0.13 \\
\hline $1987-1990$ & -6.92 & -3.93 & 0.95 & -2.74 & -1.57 & 1.19 & -0.82 \\
\hline 1988-1991 & -28.10 & -20.13 & 1.11 & -0.29 & -8.15 & 0.91 & -1.54 \\
\hline 1989-1992 & -46.59 & -39.02 & 0.22 & 11.23 & -19.93 & -0.05 & 0.96 \\
\hline $1990-1993$ & -24.98 & -23.07 & -0.03 & 9.34 & -10.43 & -3.34 & 2.56 \\
\hline 1991-1994 & 20.42 & 13.25 & 0.79 & 1.64 & 7.39 & -6.01 & 3.35 \\
\hline 1992-1995 & 27.46 & 18.55 & 2.99 & -0.27 & 7.17 & -5.09 & 4.10 \\
\hline 1993-1996 & 24.97 & 18.56 & 2.33 & 0.30 & 3.47 & -2.64 & 2.95 \\
\hline 1994-1997 & 13.55 & 9.75 & 4.07 & -1.88 & 1.39 & -1.56 & 1.77 \\
\hline $1995-1998$ & 5.92 & 4.98 & 4.49 & -3.70 & 0.67 & -1.67 & 1.14 \\
\hline 1996-1999 & 7.66 & 5.64 & 4.99 & -3.84 & 1.00 & -1.24 & 1.12 \\
\hline $1997-2000$ & 9.22 & 7.30 & 2.98 & -1.08 & 0.96 & -1.59 & 0.65 \\
\hline 1998-2001 & 13.36 & 10.20 & 4.07 & -1.43 & 1.06 & -1.02 & 0.48 \\
\hline $1999-2002$ & 16.76 & 13.78 & 4.11 & -2.13 & 1.35 & -0.37 & 0.03 \\
\hline $2000-2003$ & 15.45 & 12.85 & 3.26 & -1.28 & 0.91 & -0.50 & 0.22 \\
\hline 2001-2004 & 11.12 & 10.96 & 1.74 & -1.78 & 0.84 & -0.89 & 0.24 \\
\hline 2002-2005 & 10.24 & 9.28 & 4.15 & -3.70 & 0.76 & -1.60 & 1.35 \\
\hline \multicolumn{8}{|l|}{ Lithuania } \\
\hline 1995-1998 & 31.97 & 16.09 & 6.47 & 0.04 & 5.17 & 1.90 & 2.31 \\
\hline 1996-1999 & 27.77 & 6.62 & 9.31 & 2.37 & 4.45 & 2.94 & 2.08 \\
\hline $1997-2000$ & 19.35 & 3.38 & 8.53 & 2.52 & 2.60 & 1.43 & 0.89 \\
\hline $1998-2001$ & 25.43 & 12.05 & 10.98 & -3.07 & 3.78 & 1.75 & -0.06 \\
\hline $1999-2002$ & 31.14 & 20.47 & 13.80 & -10.30 & 3.31 & 1.19 & 2.68 \\
\hline $2000-2003$ & 31.86 & 16.39 & 12.05 & -7.57 & 4.07 & 0.82 & 6.10 \\
\hline 2001-2004 & 25.73 & 15.59 & 8.56 & -6.72 & 2.89 & 1.43 & 3.98 \\
\hline 2002-2005 & 29.67 & 18.94 & 8.23 & -5.67 & 3.53 & 1.38 & 3.27 \\
\hline \multicolumn{8}{|l|}{ Romania } \\
\hline 1992-1995 & 23.84 & 15.59 & 6.62 & 2.09 & 0.62 & -0.68 & -0.39 \\
\hline 1993-1996 & -6.53 & -13.40 & 7.17 & 0.71 & -0.54 & -0.04 & -0.44 \\
\hline 1994-1997 & 40.44 & 36.41 & 4.70 & -2.20 & 2.40 & -0.84 & -0.02 \\
\hline 1995-1998 & 16.62 & 10.74 & 7.99 & -2.00 & 0.52 & -0.57 & -0.06 \\
\hline 1996-1999 & 0.73 & -7.46 & 8.93 & 2.37 & -0.18 & -3.01 & 0.07 \\
\hline $1997-2000$ & 2.56 & -6.99 & 9.25 & 1.31 & -0.28 & -0.86 & 0.12 \\
\hline 1998-2001 & 12.21 & 6.16 & 8.10 & -1.97 & 1.13 & -1.31 & 0.10 \\
\hline 1999-2002 & 13.13 & 7.53 & 8.51 & -2.16 & 0.95 & -1.60 & -0.10 \\
\hline $2000-2003$ & 4.83 & -1.69 & 7.00 & 0.44 & 0.12 & -1.13 & 0.09 \\
\hline 2001-2004 & 13.92 & 5.38 & 9.35 & -1.29 & 0.70 & -0.89 & 0.67 \\
\hline 2002-2005 & 9.53 & 0.82 & 10.92 & -3.33 & 0.46 & -0.63 & 1.28 \\
\hline 2003-2006 & 13.60 & 1.68 & 10.72 & -2.03 & 0.87 & -0.31 & 2.67 \\
\hline
\end{tabular}




\begin{tabular}{|c|c|c|c|c|c|c|c|}
\hline & Total & Within & Between & Cross & $\begin{array}{l}\text { Prop. } \\
\text { Entry }\end{array}$ & $\begin{array}{c}\text { Disprop. } \\
\text { Entry }\end{array}$ & Exit \\
\hline \multicolumn{8}{|l|}{ Russia } \\
\hline $1985-1988$ & 10.73 & 11.64 & 0.27 & -1.22 & 0.01 & 0.04 & 0.00 \\
\hline 1986-1989 & 10.08 & 10.98 & 0.43 & -1.32 & 0.00 & 0.00 & 0.00 \\
\hline 1987-1990 & 9.54 & 9.96 & 0.51 & -0.91 & 0.01 & -0.04 & 0.00 \\
\hline 1988-1991 & 1.08 & 0.80 & 0.87 & -0.77 & 0.05 & 0.13 & 0.00 \\
\hline 1989-1992 & -11.65 & -13.10 & 0.80 & 2.41 & -1.26 & -0.50 & 0.00 \\
\hline $1990-1993$ & -21.46 & -25.09 & 1.05 & 5.59 & -2.41 & -0.59 & 0.00 \\
\hline 1991-1994 & -60.62 & -65.45 & 2.48 & 8.03 & -5.01 & -0.64 & -0.03 \\
\hline 1992-1995 & -47.95 & -54.04 & 5.66 & 1.99 & -1.87 & 0.14 & 0.18 \\
\hline 1993-1996 & -45.20 & -50.75 & 6.51 & -0.43 & -1.45 & 0.43 & 0.51 \\
\hline 1994-1997 & -4.23 & -13.47 & 8.40 & -0.62 & -0.23 & 0.76 & 0.93 \\
\hline 1995-1998 & -7.26 & -15.63 & 7.68 & -0.97 & -0.28 & 0.49 & 1.45 \\
\hline 1996-1999 & 15.53 & 7.76 & 8.58 & -5.04 & 0.93 & 1.03 & 2.26 \\
\hline $1997-2000$ & 17.96 & 10.52 & 8.17 & -5.17 & 1.38 & -0.17 & 3.23 \\
\hline $1998-2001$ & 31.47 & 23.60 & 7.40 & -5.45 & 2.41 & -0.19 & 3.70 \\
\hline 1999-2002 & 18.31 & 7.81 & 7.24 & -4.63 & 1.70 & 0.52 & 5.67 \\
\hline $2000-2003$ & 16.80 & 4.94 & 7.44 & -3.31 & 1.54 & 1.32 & 4.87 \\
\hline 2001-2004 & 15.29 & 5.62 & 6.30 & -4.12 & 1.49 & 1.04 & 4.96 \\
\hline \multicolumn{8}{|l|}{ Ukraine } \\
\hline 1989-1992 & 10.32 & 9.07 & 0.56 & 0.68 & n.a. & n.a. & n.a. \\
\hline 1992-1995 & -77.40 & -81.95 & 2.74 & 3.70 & -2.22 & 0.32 & 0.02 \\
\hline 1993-1996 & -90.36 & -96.80 & 3.55 & 6.23 & -4.06 & 0.71 & 0.00 \\
\hline 1994-1997 & -56.34 & -65.73 & 3.33 & 8.75 & -4.18 & 1.16 & 0.34 \\
\hline 1995-1998 & -22.30 & -35.15 & 5.53 & 6.17 & -2.11 & 2.31 & 0.95 \\
\hline 1996-1999 & 0.68 & -10.80 & 6.65 & 0.83 & -0.02 & 2.82 & 1.20 \\
\hline $1997-2000$ & -19.04 & -30.38 & 14.04 & -5.26 & -1.32 & 2.28 & 1.59 \\
\hline 1998-2001 & 1.93 & -14.59 & 18.15 & -6.39 & -0.18 & 1.19 & 3.76 \\
\hline 1999-2002 & 9.71 & -10.93 & 28.32 & -12.33 & 0.56 & 0.43 & 3.67 \\
\hline $2000-2003$ & 63.54 & 37.39 & 20.12 & -3.30 & 4.55 & 0.24 & 4.54 \\
\hline 2001-2004 & 64.82 & 43.88 & 17.34 & -3.55 & 3.53 & 0.30 & 3.33 \\
\hline $2002-2005$ & 50.87 & 32.43 & 15.18 & -5.43 & 3.88 & 1.12 & 3.69 \\
\hline 2003-2006 & 89.31 & 72.89 & 13.93 & -8.22 & 7.00 & 1.39 & 2.32 \\
\hline
\end{tabular}

Note: These are multifactor productivity growth decompositions weighted by base-year employment. 
Appendix Table 4: Five-Year Labor Productivity Growth Decompositions

\begin{tabular}{|c|c|c|c|c|c|c|c|}
\hline & Total & Within & Between & Cross & $\begin{array}{l}\text { Prop. } \\
\text { Entry }\end{array}$ & $\begin{array}{l}\text { Disprop. } \\
\text { Entry }\end{array}$ & Exit \\
\hline \multicolumn{8}{|l|}{ Hungary } \\
\hline 1986-1991 & -29.33 & -15.50 & 2.29 & -5.00 & -9.54 & -0.12 & -1.45 \\
\hline $1987-1992$ & -25.23 & -18.04 & 2.21 & 1.28 & -11.28 & 1.93 & -1.34 \\
\hline 1988-1993 & -17.97 & -18.04 & 1.17 & 6.95 & -9.55 & 2.72 & -1.21 \\
\hline 1989-1994 & -15.70 & -18.67 & -0.50 & 9.78 & -9.35 & 1.04 & 2.00 \\
\hline 1990-1995 & 17.40 & 4.89 & 2.29 & 0.63 & 10.65 & -2.45 & 1.40 \\
\hline 1991-1996 & 40.64 & 26.75 & 3.64 & -6.06 & 18.73 & -4.30 & 1.88 \\
\hline 1992-1997 & 38.28 & 29.32 & 13.32 & -14.66 & 14.38 & -5.54 & 1.45 \\
\hline 1993-1998 & 25.17 & 21.07 & 4.17 & -5.99 & 6.49 & -4.53 & 3.96 \\
\hline 1994-1999 & 9.42 & 8.72 & 8.33 & -9.51 & 2.25 & -4.00 & 3.62 \\
\hline $1995-2000$ & 15.43 & 16.23 & 9.09 & -11.05 & 3.45 & -5.56 & 3.27 \\
\hline 1996-2001 & 23.64 & 22.80 & 7.47 & -9.36 & 4.61 & -5.07 & 3.19 \\
\hline $1997-2002$ & 27.63 & 24.49 & 6.02 & -7.17 & 4.76 & -4.02 & 3.56 \\
\hline $1998-2003$ & 29.17 & 27.15 & 5.22 & -6.61 & 4.79 & -4.11 & 2.73 \\
\hline $1999-2004$ & 28.30 & 29.54 & 3.96 & -8.07 & 4.94 & -4.97 & 2.90 \\
\hline $2000-2005$ & 28.15 & 29.68 & 3.10 & -5.36 & 3.55 & -6.69 & 3.87 \\
\hline \multicolumn{8}{|l|}{ Lithuania } \\
\hline $1995-2000$ & 52.04 & 22.90 & 8.96 & 4.88 & 12.28 & -4.46 & 7.48 \\
\hline 1996-2001 & 55.56 & 26.72 & 7.90 & 6.29 & 13.10 & -3.89 & 5.44 \\
\hline $1997-2002$ & 45.77 & 29.22 & 6.81 & -0.09 & 10.50 & -5.76 & 5.10 \\
\hline $1998-2003$ & 39.59 & 26.52 & 7.50 & -1.89 & 9.97 & -7.78 & 5.27 \\
\hline $1999-2004$ & 50.01 & 32.22 & 8.51 & -5.17 & 10.09 & -5.01 & 9.36 \\
\hline $2000-2005$ & 55.79 & 31.70 & 9.05 & -3.95 & 11.98 & -5.32 & 12.32 \\
\hline \multicolumn{8}{|l|}{ Romania } \\
\hline $1992-1997$ & 39.58 & 25.74 & 9.01 & -0.48 & 4.25 & 0.48 & 0.57 \\
\hline 1993-1998 & 9.13 & -4.08 & 10.46 & -0.19 & 0.80 & 1.38 & 0.76 \\
\hline 1994-1999 & 12.70 & 4.18 & 10.55 & -1.28 & 1.96 & -2.78 & 0.08 \\
\hline $1995-2000$ & 9.30 & 2.89 & 12.79 & -6.80 & 0.93 & -0.86 & 0.35 \\
\hline 1996-2001 & -0.55 & -2.83 & 12.76 & -6.76 & -0.41 & -3.83 & 0.52 \\
\hline $1997-2002$ & 9.65 & 3.54 & 12.88 & -4.17 & 0.65 & -3.85 & 0.60 \\
\hline $1998-2003$ & 21.48 & 9.20 & 12.39 & -1.99 & 3.80 & -2.68 & 0.76 \\
\hline $1999-2004$ & 32.28 & 25.47 & 13.64 & -8.14 & 3.99 & -4.24 & 1.57 \\
\hline $2000-2005$ & 21.40 & 13.40 & 12.55 & -5.67 & 2.36 & -4.36 & 3.12 \\
\hline $2001-2006$ & 32.03 & 19.24 & 14.30 & -5.91 & 4.07 & -4.81 & 5.12 \\
\hline
\end{tabular}




\begin{tabular}{llllllll}
\hline & Total & Within & Between & Cross & $\begin{array}{c}\text { Prop. } \\
\text { Entry }\end{array}$ & $\begin{array}{c}\text { Disprop. } \\
\text { Entry }\end{array}$ & Exit \\
\hline Russia & & & & & & & \\
$1985-1990$ & 20.17 & 21.10 & 0.24 & -1.18 & 0.04 & -0.02 & 0.00 \\
$1986-1991$ & 10.90 & 11.95 & 0.23 & -1.29 & 0.16 & -0.14 & 0.00 \\
$1987-1992$ & 6.32 & 6.54 & 1.82 & 0.30 & -0.14 & -2.21 & 0.00 \\
$1988-1993$ & -17.87 & -19.36 & 2.22 & 4.54 & -2.39 & -2.87 & 0.00 \\
$1989-1994$ & -56.28 & -59.80 & 2.81 & 12.15 & -7.81 & -3.64 & 0.00 \\
$1990-1995$ & -63.72 & -69.85 & 2.65 & 18.29 & -11.00 & -4.27 & 0.45 \\
$1991-1996$ & -66.44 & -76.95 & 2.62 & 16.24 & -8.46 & -1.30 & 1.41 \\
$1992-1997$ & -54.65 & -66.69 & 7.44 & 7.02 & -3.84 & -0.63 & 2.06 \\
$1993-1998$ & -45.40 & -57.81 & 7.55 & 6.85 & -3.93 & -1.06 & 2.99 \\
$1994-1999$ & -1.24 & -17.08 & 7.17 & 4.54 & -0.38 & -0.82 & 5.32 \\
$1995-2000$ & 15.55 & -1.37 & 7.15 & 3.37 & 1.71 & -1.68 & 6.36 \\
$1996-2001$ & 37.37 & 18.29 & 7.89 & 0.76 & 5.08 & -2.55 & 7.91 \\
$1997-2002$ & 28.14 & 9.27 & 6.86 & 0.37 & 4.56 & -3.30 & 10.37 \\
$1998-2003$ & 47.20 & 24.06 & 6.19 & -0.11 & 7.83 & -2.28 & 11.51 \\
$1999-2004$ & 42.19 & 15.29 & 9.72 & -2.42 & 7.71 & -2.36 & 14.24 \\
\hline Ukraine & & & & & & & \\
$1989-1994$ & -58.04 & -62.15 & 1.44 & 6.05 & -2.35 & -1.04 & 0.01 \\
$1992-1997$ & -101.30 & -112.22 & 3.58 & 22.56 & -14.75 & -0.90 & 0.44 \\
$1993-1998$ & -88.32 & -102.79 & 5.04 & 21.01 & -12.67 & -0.08 & 1.18 \\
$1994-1999$ & -41.92 & -58.45 & 5.24 & 14.20 & -6.98 & 2.43 & 1.63 \\
$1995-2000$ & -29.81 & -47.47 & 14.42 & 1.53 & -4.10 & 3.74 & 2.08 \\
$1996-2001$ & 11.30 & -16.80 & 13.73 & 3.14 & 1.59 & 4.32 & 5.32 \\
$1997-2002$ & 27.11 & -4.99 & 22.88 & -1.97 & 4.25 & 1.21 & 5.73 \\
$1998-2003$ & 52.56 & 15.74 & 26.51 & -4.75 & 7.87 & -1.30 & 8.48 \\
$1999-2004$ & 69.83 & 31.64 & 33.03 & -13.47 & 9.86 & -1.06 & 9.84 \\
$2000-2005$ & 93.63 & 54.25 & 22.29 & -4.73 & 14.63 & -1.27 & 8.47 \\
$2001-2006$ & 134.15 & 95.48 & 19.60 & -7.25 & 19.64 & -2.04 & 8.72 \\
\hline
\end{tabular}

Note: These are labor productivity growth decompositions weighted by base-year employment. Labor productivity is the log of the ratio of real gross output divided by number of employees. They apply Equation (4) in the text. The exit term here is $-\sum_{e \in X} s_{e t-1}\left(p_{e t-1}-P_{i t-1}\right)$, so a positive exit term value means a positive contribution to productivity growth. 
Appendix Table 5: Five-Year Multifactor Productivity Growth Decompositions

\begin{tabular}{|c|c|c|c|c|c|c|c|}
\hline & Total & Within & Between & Cross & $\begin{array}{l}\text { Prop. } \\
\text { Entry }\end{array}$ & $\begin{array}{c}\text { Disprop. } \\
\text { Entry }\end{array}$ & Exit \\
\hline \multicolumn{8}{|l|}{ United Kingdom } \\
\hline $1982-1987$ & 15.41 & 6.24 & -0.52 & 7.83 & 2.27 & \multicolumn{2}{|c|}{$-0.40 *$} \\
\hline \multicolumn{8}{|l|}{ United States } \\
\hline 1977-1982 & 2.43 & -0.30 & -1.26 & 3.52 & 0.19 & \multicolumn{2}{|c|}{$0.24 *$} \\
\hline $1982-1987$ & 8.26 & 4.76 & -1.39 & 3.92 & 0.69 & & \\
\hline \multicolumn{8}{|l|}{ Hungary } \\
\hline 1986-1991 & -23.12 & -16.11 & 1.98 & -1.67 & -7.37 & 1.32 & -1.28 \\
\hline 1987-1992 & -39.19 & -29.05 & 0.77 & 7.38 & -18.85 & 1.83 & -1.27 \\
\hline $1988-1993$ & -36.21 & -28.60 & 0.22 & 12.31 & -21.32 & 1.91 & -0.73 \\
\hline 1989-1994 & -26.52 & -28.15 & -0.94 & 16.57 & -16.80 & 0.64 & 2.16 \\
\hline 1990-1995 & 1.03 & -7.99 & -2.06 & 8.92 & 1.25 & -2.36 & 3.27 \\
\hline 1991-1996 & 27.72 & 16.22 & 0.25 & 0.04 & 11.89 & -3.92 & 3.24 \\
\hline 1992-1997 & 33.54 & 22.01 & 2.19 & -1.67 & 11.70 & -4.58 & 3.89 \\
\hline 1993-1998 & 31.47 & 23.56 & 2.95 & -3.20 & 7.58 & -2.64 & 3.23 \\
\hline 1994-1999 & 14.35 & 10.00 & 5.45 & -4.55 & 3.04 & -2.07 & 2.49 \\
\hline $1995-2000$ & 14.05 & 10.28 & 6.28 & -4.36 & 2.96 & -2.71 & 1.61 \\
\hline 1996-2001 & 19.04 & 13.76 & 5.93 & -3.53 & 3.51 & -2.18 & 1.54 \\
\hline $1997-2002$ & 17.82 & 11.95 & 4.43 & -1.24 & 2.92 & -1.16 & 0.91 \\
\hline $1998-2003$ & 20.84 & 15.67 & 5.49 & -2.75 & 3.19 & -0.81 & 0.05 \\
\hline 1999-2004 & 21.88 & 19.14 & 4.07 & -4.97 & 3.85 & -0.36 & 0.15 \\
\hline 2000-2005 & 24.76 & 20.78 & 6.06 & -4.38 & 3.16 & -2.07 & 1.20 \\
\hline \multicolumn{8}{|l|}{ Lithuania } \\
\hline $1995-2000$ & 47.74 & 14.91 & 11.50 & 4.47 & 11.79 & 2.81 & 2.27 \\
\hline 1996-2001 & 55.10 & 24.05 & 12.62 & -1.83 & 13.54 & 3.47 & 3.25 \\
\hline $1997-2002$ & 45.23 & 25.22 & 11.71 & -8.04 & 10.72 & 2.41 & 3.20 \\
\hline $1998-2003$ & 41.79 & 21.94 & 11.89 & -7.43 & 10.72 & 1.35 & 3.32 \\
\hline $1999-2004$ & 49.10 & 27.31 & 13.67 & -10.51 & 9.48 & 2.64 & 6.51 \\
\hline $2000-2005$ & 54.55 & 28.47 & 14.16 & -10.01 & 11.13 & 2.58 & 8.21 \\
\hline \multicolumn{8}{|l|}{ Romania } \\
\hline 1992-1997 & 49.90 & 36.89 & 6.80 & 2.40 & 5.06 & -0.83 & -0.42 \\
\hline 1993-1998 & -0.08 & -13.35 & 8.13 & 6.00 & -1.25 & 0.60 & -0.21 \\
\hline 1994-1999 & 30.24 & 18.73 & 6.15 & 2.51 & 5.21 & -2.44 & 0.07 \\
\hline $1995-2000$ & 24.83 & 12.20 & 10.92 & -0.62 & 3.03 & -0.67 & -0.04 \\
\hline 1996-2001 & 11.66 & 4.14 & 11.36 & -2.44 & 1.72 & -3.17 & 0.06 \\
\hline $1997-2002$ & 5.45 & -6.71 & 11.44 & 3.09 & 0.03 & -2.45 & 0.05 \\
\hline $1998-2003$ & 16.14 & -1.29 & 11.28 & 3.98 & 2.79 & -0.78 & 0.15 \\
\hline 1999-2004 & 25.31 & 13.59 & 12.04 & -2.40 & 3.03 & -1.21 & 0.26 \\
\hline $2000-2005$ & 15.86 & 3.11 & 10.04 & -1.38 & 1.70 & -0.22 & 2.61 \\
\hline 2001-2006 & 21.03 & 4.84 & 11.67 & -1.74 & 2.63 & 0.06 & 3.58 \\
\hline
\end{tabular}




\begin{tabular}{|c|c|c|c|c|c|c|c|}
\hline & Total & Within & Between & Cross & $\begin{array}{l}\text { Prop. } \\
\text { Entry }\end{array}$ & $\begin{array}{c}\text { Disprop. } \\
\text { Entry }\end{array}$ & Exit \\
\hline \multicolumn{8}{|l|}{ Russia } \\
\hline $1985-1990$ & 13.60 & 14.58 & 0.69 & -1.68 & 0.03 & 0.00 & 0.00 \\
\hline 1986-1991 & 6.64 & 7.26 & 0.73 & -1.62 & 0.13 & 0.15 & 0.00 \\
\hline 1987-1992 & -1.91 & -3.38 & 1.63 & 0.75 & -0.33 & -0.57 & 0.00 \\
\hline 1988-1993 & -19.36 & -22.59 & 1.18 & 4.71 & -1.95 & -0.71 & 0.00 \\
\hline 1989-1994 & -52.60 & -57.02 & 1.98 & 10.19 & -6.47 & -1.38 & 0.10 \\
\hline $1990-1995$ & -54.96 & -62.26 & 2.11 & 14.09 & -8.22 & -1.01 & 0.32 \\
\hline 1991-1996 & -75.43 & -83.49 & 3.11 & 10.83 & -7.48 & 1.17 & 0.42 \\
\hline 1992-1997 & -47.05 & -57.01 & 7.39 & 3.16 & -2.98 & 1.22 & 1.18 \\
\hline 1993-1998 & -39.32 & -49.27 & 8.25 & 2.33 & -3.15 & 1.45 & 1.06 \\
\hline 1994-1999 & 4.03 & -9.32 & 8.23 & 0.14 & 0.26 & 1.90 & 2.83 \\
\hline $1995-2000$ & 17.90 & 3.79 & 7.95 & -0.30 & 1.86 & 0.92 & 3.68 \\
\hline 1996-2001 & 37.86 & 20.81 & 8.29 & -4.01 & 5.75 & 1.20 & 5.82 \\
\hline $1997-2002$ & 28.12 & 10.69 & 8.77 & -5.03 & 5.11 & 1.09 & 7.49 \\
\hline $1998-2003$ & 44.69 & 24.93 & 7.90 & -4.58 & 6.63 & 1.57 & 8.24 \\
\hline 1999-2004 & 38.26 & 15.05 & 9.74 & -5.17 & 6.05 & 2.10 & 10.50 \\
\hline \multicolumn{8}{|l|}{ Ukraine } \\
\hline 1989-1994 & -44.33 & -47.51 & 1.42 & 2.76 & -0.74 & -0.24 & -0.02 \\
\hline 1992-1997 & -94.95 & -104.72 & 3.23 & 13.90 & -8.61 & 1.04 & 0.21 \\
\hline 1993-1998 & -83.08 & -97.16 & 4.73 & 16.04 & -9.73 & 2.39 & 0.65 \\
\hline 1994-1999 & -42.65 & -58.78 & 5.16 & 12.93 & -6.94 & 3.56 & 1.41 \\
\hline $1995-2000$ & -38.65 & -55.56 & 9.95 & 6.49 & -6.02 & 4.28 & 2.21 \\
\hline 1996-2001 & 6.55 & -23.08 & 14.17 & 4.98 & 1.02 & 4.42 & 5.04 \\
\hline $1997-2002$ & 22.31 & -11.44 & 21.55 & -0.09 & 3.53 & 3.12 & 5.64 \\
\hline $1998-2003$ & 46.35 & 10.44 & 23.84 & -3.77 & 6.77 & 1.57 & 7.49 \\
\hline 1999-2004 & 66.61 & 27.21 & 32.47 & -11.53 & 8.30 & 1.31 & 8.85 \\
\hline $2000-2005$ & 89.73 & 50.11 & 22.45 & -4.41 & 12.67 & 1.45 & 7.45 \\
\hline 2001-2006 & 131.80 & 90.20 & 20.60 & -7.23 & 18.73 & 1.82 & 7.69 \\
\hline
\end{tabular}

Note: These are multifactor productivity growth decompositions weighted by base-year employment, with the exception of the U.S. numbers, which are weighted by base-year output. The U.K. and U.S. numbers are our calculations based on Disney et al. (2003) and Haltiwanger (1997)'s results, respectively. The U.K. and U.S. starred numbers are exit plus disproportionate entry. 


\section{Appendix Table 6: Entry Cohort Contributions to Three-Year Labor Productivity Growth}

\begin{tabular}{|c|c|c|c|c|c|}
\hline & $\begin{array}{c}\text { Year } \\
\text { T Cohort }\end{array}$ & $\begin{array}{c}\text { Year } \\
\text { T-1 Cohort }\end{array}$ & $\begin{array}{c}\text { Year } \\
\text { T-2 Cohort }\end{array}$ & $\begin{array}{c}\text { Total } \\
\text { Disprop. } \\
\text { Entry } \\
\end{array}$ & $\begin{array}{c}(\mathrm{T}-2)-\mathrm{T} \\
\text { Entry }\end{array}$ \\
\hline \multicolumn{6}{|l|}{ Georgia } \\
\hline $2000-2003$ & -0.93 & -0.82 & 2.00 & 0.25 & n.a. \\
\hline 2001-2004 & -2.61 & -0.78 & 0.46 & -2.93 & n.a. \\
\hline \multicolumn{6}{|l|}{ Hungary } \\
\hline 1986-1989 & 0.03 & 0.19 & -0.17 & 0.05 & n.a. \\
\hline 1987-1990 & -1.57 & 0.47 & 0.38 & -0.71 & n.a. \\
\hline 1988-1991 & -2.51 & 1.24 & 0.84 & -0.44 & 0.81 \\
\hline 1989-1992 & -3.81 & 1.50 & 3.19 & 0.88 & 4.76 \\
\hline 1990-1993 & -5.89 & 2.28 & 1.79 & -1.82 & 4.30 \\
\hline 1991-1994 & -3.66 & -2.13 & 0.63 & -5.16 & 4.44 \\
\hline 1992-1995 & -2.59 & -1.29 & -1.73 & -5.61 & 4.16 \\
\hline 1993-1996 & -1.75 & -1.13 & -1.21 & -4.10 & 2.44 \\
\hline 1994-1997 & -1.63 & -1.11 & -0.19 & -2.93 & 2.40 \\
\hline 1995-1998 & -1.40 & -1.21 & -0.95 & -3.56 & 0.80 \\
\hline 1996-1999 & -1.39 & -1.03 & -0.73 & -3.15 & 0.90 \\
\hline $1997-2000$ & -1.55 & -0.84 & -1.09 & -3.48 & 0.31 \\
\hline 1998-2001 & -1.78 & -0.78 & -0.43 & -3.00 & 0.96 \\
\hline 1999-2002 & -1.43 & -1.00 & -0.38 & -2.81 & 1.18 \\
\hline $2000-2003$ & -1.68 & -0.89 & -0.73 & -3.30 & 1.06 \\
\hline 2001-2004 & -3.46 & -1.35 & 0.01 & -4.80 & 1.44 \\
\hline $2002-2005$ & -2.36 & -2.88 & -0.85 & -6.09 & 0.83 \\
\hline \multicolumn{6}{|l|}{ Lithuania } \\
\hline 1995-1998 & -1.40 & -0.17 & -0.73 & -2.31 & n.a. \\
\hline 1996-1999 & -1.88 & 0.20 & 0.30 & -1.38 & n.a. \\
\hline $1997-2000$ & -1.70 & -2.01 & -0.46 & -4.16 & 0.95 \\
\hline 1998-2001 & -1.93 & -1.12 & -1.52 & -4.56 & 0.36 \\
\hline 1999-2002 & -2.12 & -1.22 & -1.02 & -4.36 & 0.68 \\
\hline $2000-2003$ & -2.49 & -1.98 & -0.99 & -5.46 & 0.94 \\
\hline 2001-2004 & -0.92 & -1.93 & -1.42 & -4.27 & 0.70 \\
\hline 2002-2005 & -1.70 & -0.91 & -1.37 & -3.98 & 1.12 \\
\hline \multicolumn{6}{|l|}{ Romania } \\
\hline 1992-1995 & -0.35 & -0.14 & 0.42 & -0.07 & n.a. \\
\hline 1993-1996 & -0.33 & 0.10 & 0.61 & 0.37 & n.a. \\
\hline 1994-1997 & -0.54 & -0.45 & 0.42 & -0.56 & 0.78 \\
\hline 1995-1998 & -0.71 & 0.09 & -0.04 & -0.65 & 0.29 \\
\hline 1996-1999 & -0.95 & -0.21 & -2.16 & -3.32 & -1.62 \\
\hline $1997-2000$ & -0.90 & -0.40 & 0.04 & -1.26 & 0.74 \\
\hline $1998-2001$ & -1.55 & -0.82 & 0.18 & -2.19 & 1.13 \\
\hline 1999-2002 & -1.63 & -0.95 & -0.31 & -2.89 & 0.58 \\
\hline $2000-2003$ & -1.45 & -1.06 & -0.37 & -2.87 & 1.18 \\
\hline 2001-2004 & -1.95 & -0.97 & -0.52 & -3.44 & 1.10 \\
\hline 2002-2005 & -2.11 & -1.21 & -0.82 & -4.15 & 0.62 \\
\hline 2003-2006 & -2.17 & -1.43 & -0.83 & -4.44 & 1.12 \\
\hline
\end{tabular}




\begin{tabular}{|c|c|c|c|c|c|}
\hline & $\begin{array}{c}\text { Year } \\
\text { T Cohort }\end{array}$ & $\begin{array}{c}\text { Year } \\
\text { T-1 Cohort }\end{array}$ & $\begin{array}{c}\text { Year } \\
\text { T-2 Cohort }\end{array}$ & $\begin{array}{c}\text { Total } \\
\text { Disprop. } \\
\text { Entry }\end{array}$ & $\begin{array}{c}(\mathrm{T}-2)-\mathrm{T} \\
\text { Entry }\end{array}$ \\
\hline \multicolumn{6}{|l|}{ Russia } \\
\hline 1985-1988 & 0.00 & 0.00 & 0.03 & 0.04 & n.a. \\
\hline 1986-1989 & -0.01 & 0.00 & 0.00 & -0.01 & n.a. \\
\hline $1987-1990$ & -0.05 & 0.00 & 0.00 & -0.05 & 0.00 \\
\hline 1988-1991 & -0.12 & -0.01 & -0.01 & -0.14 & 0.00 \\
\hline 1989-1992 & -1.32 & -0.86 & -0.06 & -2.24 & -0.01 \\
\hline 1990-1993 & -0.65 & -1.29 & -1.01 & -2.95 & -0.88 \\
\hline 1991-1994 & -0.66 & -0.51 & -1.11 & -2.29 & 0.20 \\
\hline $1992-1995$ & -0.36 & -0.52 & -0.24 & -1.12 & 0.41 \\
\hline 1993-1996 & -0.04 & -0.20 & -0.40 & -0.64 & 0.27 \\
\hline 1994-1997 & -0.09 & -0.20 & 0.04 & -0.25 & 0.40 \\
\hline $1995-1998$ & -0.29 & -0.57 & -0.14 & -1.00 & -0.10 \\
\hline 1996-1999 & -0.22 & -0.86 & -0.15 & -1.23 & -0.06 \\
\hline $1997-2000$ & -0.68 & -0.57 & -0.69 & -1.95 & -0.40 \\
\hline 1998-2001 & -0.96 & -0.98 & -0.51 & -2.45 & -0.28 \\
\hline 1999-2002 & -1.14 & -0.64 & -0.75 & -2.53 & -0.07 \\
\hline $2000-2003$ & -1.13 & -0.82 & 0.01 & -1.94 & 0.97 \\
\hline 2001-2004 & -0.91 & -1.34 & -0.33 & -2.58 & 0.81 \\
\hline \multicolumn{6}{|l|}{ Ukraine } \\
\hline $1992-1995$ & -0.31 & -0.05 & 0.04 & -0.33 & n.a. \\
\hline 1993-1996 & -0.04 & -0.50 & -0.03 & -0.57 & n.a. \\
\hline 1994-1997 & 0.23 & -0.11 & -0.24 & -0.11 & 0.08 \\
\hline 1995-1998 & -0.44 & 0.58 & -0.03 & 0.11 & 0.01 \\
\hline 1996-1999 & 0.61 & 0.43 & 1.38 & 2.42 & 1.15 \\
\hline $1997-2000$ & -0.15 & 0.65 & 0.98 & 1.47 & 1.42 \\
\hline $1998-2001$ & -0.52 & -0.25 & 0.98 & 0.21 & 0.38 \\
\hline 1999-2002 & -1.24 & 0.08 & -0.03 & -1.19 & 0.12 \\
\hline $2000-2003$ & -1.49 & -0.87 & -0.06 & -2.42 & 0.46 \\
\hline 2001-2004 & -0.38 & -0.70 & -0.60 & -1.68 & 0.64 \\
\hline $2002-2005$ & -0.89 & -0.14 & -0.20 & -1.23 & 1.30 \\
\hline 2003-2006 & -0.84 & -0.65 & -0.08 & -1.57 & 0.31 \\
\hline
\end{tabular}

Note: These are disproportionate entry terms from labor productivity growth decompositions weighted by baseyear employment, applying Equation (4) in the text. (T-2) - T entry is the difference between the year T-2 contributions and what they were two years earlier as year T contributions. 
Appendix Table 7: Reallocation and Labor Productivity Descriptive Statistics

\begin{tabular}{|c|c|c|c|c|}
\hline & $\begin{array}{l}\text { Productivity } \\
\text { Dispersion }\end{array}$ & $\begin{array}{l}\text { Productivity } \\
\text { Rank Change }\end{array}$ & $\begin{array}{l}\text { Employment } \\
\text { Share Change } \\
\text { Dispersion }\end{array}$ & $\begin{array}{c}\text { Employment } \\
\text { Share Change- } \\
\text { Productivity } \\
\text { Correlation }\end{array}$ \\
\hline \multicolumn{5}{|l|}{ Georgia } \\
\hline $2000-2003$ & 1.47 & 0.37 & 1.94 & 0.16 \\
\hline 2001-2004 & 1.37 & 0.31 & 1.64 & 0.17 \\
\hline \multicolumn{5}{|l|}{ Hungary } \\
\hline 1986-1989 & 0.72 & 0.21 & 0.47 & 0.15 \\
\hline 1987-1990 & 0.84 & 0.20 & 1.37 & 0.02 \\
\hline 1988-1991 & 0.89 & 0.35 & 1.77 & 0.01 \\
\hline 1989-1992 & 1.06 & 0.41 & 2.60 & 0.01 \\
\hline 1990-1993 & 1.05 & 0.45 & 2.66 & 0.01 \\
\hline 1991-1994 & 1.07 & 0.36 & 2.43 & 0.01 \\
\hline 1992-1995 & 1.15 & 0.36 & 2.26 & 0.04 \\
\hline 1993-1996 & 1.13 & 0.33 & 1.74 & 0.01 \\
\hline 1994-1997 & 1.12 & 0.29 & 1.67 & 0.03 \\
\hline $1995-1998$ & 1.14 & 0.29 & 1.80 & 0.03 \\
\hline 1996-1999 & 1.13 & 0.28 & 1.76 & 0.02 \\
\hline $1997-2000$ & 1.13 & 0.28 & 1.76 & 0.01 \\
\hline $1998-2001$ & 1.11 & 0.27 & 1.73 & 0.02 \\
\hline $1999-2002$ & 1.11 & 0.27 & 1.82 & 0.02 \\
\hline $2000-2003$ & 1.12 & 0.26 & 1.81 & 0.00 \\
\hline 2001-2004 & 1.20 & 0.26 & 2.12 & -0.01 \\
\hline 2002-2005 & 1.19 & 0.25 & 2.11 & 0.00 \\
\hline \multicolumn{5}{|l|}{ Lithuania } \\
\hline 1995-1998 & 1.11 & 0.37 & 1.26 & 0.08 \\
\hline 1996-1999 & 1.15 & 0.42 & 1.23 & 0.07 \\
\hline $1997-2000$ & 1.27 & 0.43 & 1.25 & 0.03 \\
\hline $1998-2001$ & 1.21 & 0.38 & 1.31 & 0.03 \\
\hline 1999-2002 & 1.18 & 0.36 & 1.47 & 0.06 \\
\hline $2000-2003$ & 1.46 & 0.34 & 1.47 & 0.06 \\
\hline 2001-2004 & 1.43 & 0.31 & 1.36 & 0.04 \\
\hline 2002-2005 & 1.32 & 0.32 & 1.33 & 0.03 \\
\hline \multicolumn{5}{|l|}{ Romania } \\
\hline 1992-1995 & 1.23 & 0.50 & 1.95 & 0.07 \\
\hline 1993-1996 & 1.28 & 0.48 & 2.22 & 0.06 \\
\hline 1994-1997 & 1.23 & 0.44 & 1.34 & 0.04 \\
\hline 1995-1998 & 1.21 & 0.43 & 2.15 & 0.05 \\
\hline 1996-1999 & 1.19 & 0.39 & 1.88 & 0.03 \\
\hline $1997-2000$ & 1.22 & 0.39 & 2.11 & 0.04 \\
\hline 1998-2001 & 1.20 & 0.39 & 1.76 & 0.04 \\
\hline 1999-2002 & 1.22 & 0.38 & 1.66 & 0.04 \\
\hline $2000-2003$ & 1.22 & 0.38 & 1.81 & 0.03 \\
\hline 2001-2004 & 1.30 & 0.36 & 1.94 & 0.04 \\
\hline 2002-2005 & 1.27 & 0.35 & 1.95 & 0.05 \\
\hline 2003-2006 & 1.30 & 0.35 & 1.90 & 0.05 \\
\hline
\end{tabular}




\begin{tabular}{|c|c|c|c|c|}
\hline & $\begin{array}{c}\text { Productivity } \\
\text { Dispersion }\end{array}$ & $\begin{array}{l}\text { Productivity } \\
\text { Rank Change }\end{array}$ & $\begin{array}{c}\text { Employment } \\
\text { Share Change } \\
\text { Dispersion }\end{array}$ & $\begin{array}{c}\text { Employment } \\
\text { Share Change- } \\
\text { Productivity } \\
\text { Correlation }\end{array}$ \\
\hline \multicolumn{5}{|l|}{ Russia } \\
\hline 1985-1988 & 0.66 & 0.08 & 0.28 & 0.01 \\
\hline 1986-1989 & 0.65 & 0.09 & 0.34 & 0.03 \\
\hline 1987-1990 & 0.65 & 0.11 & 0.35 & 0.04 \\
\hline 1988-1991 & 0.62 & 0.18 & 0.40 & 0.00 \\
\hline 1989-1992 & 0.73 & 0.36 & 0.69 & -0.04 \\
\hline 1990-1993 & 0.81 & 0.45 & 0.65 & -0.04 \\
\hline 1991-1994 & 0.92 & 0.50 & 0.69 & -0.01 \\
\hline 1992-1995 & 1.00 & 0.42 & 0.66 & 0.08 \\
\hline 1993-1996 & 1.05 & 0.44 & 0.66 & 0.12 \\
\hline 1994-1997 & 1.11 & 0.34 & 0.72 & 0.13 \\
\hline 1995-1998 & 1.11 & 0.30 & 0.83 & 0.11 \\
\hline 1996-1999 & 1.19 & 0.28 & 1.00 & 0.09 \\
\hline $1997-2000$ & 1.27 & 0.25 & 0.93 & 0.09 \\
\hline 1998-2001 & 1.29 & 0.26 & 0.91 & 0.09 \\
\hline 1999-2002 & 1.33 & 0.23 & 1.04 & 0.10 \\
\hline $2000-2003$ & 1.31 & 0.22 & 1.00 & 0.09 \\
\hline 2001-2004 & 1.36 & 0.23 & 1.10 & 0.09 \\
\hline \multicolumn{5}{|l|}{ Ukraine } \\
\hline 1989-1992 & 0.51 & 0.37 & 0.44 & 0.03 \\
\hline 1992-1995 & 0.80 & 0.43 & 0.37 & 0.09 \\
\hline 1993-1996 & 0.93 & 0.42 & 0.48 & 0.09 \\
\hline 1994-1997 & 1.15 & 0.37 & 0.64 & 0.06 \\
\hline 1995-1998 & 1.38 & 0.35 & 0.98 & 0.08 \\
\hline 1996-1999 & 1.50 & 0.31 & 0.86 & 0.08 \\
\hline $1997-2000$ & 1.56 & 0.38 & 1.11 & 0.11 \\
\hline 1998-2001 & 1.57 & 0.40 & 1.51 & 0.11 \\
\hline $1999-2002$ & 1.73 & 0.26 & 1.44 & 0.13 \\
\hline $2000-2003$ & 1.72 & 0.27 & 1.43 & 0.09 \\
\hline 2001-2004 & 1.69 & 0.24 & 1.31 & 0.08 \\
\hline 2002-2005 & 1.68 & 0.23 & 1.34 & 0.08 \\
\hline 2003-2006 & 1.65 & 0.36 & 1.37 & 0.07 \\
\hline
\end{tabular}

Note: Productivity dispersion is the standard deviation of labor productivity in the first year of the three-year period. Productivity rank change is 1 minus the correlation in labor productivity rankings in the first and last years of the three-year periods. Employment share change is the standard deviation of employment share change in the threeyear period. Employment share change-productivity correlation is the correlation between a firm's deviation from average labor productivity in the sector and its employment share change. 